Supporting Information for

\title{
Aviation emissions impact ambient ultrafine particle concentrations in the greater Boston area
}

N. Hudda ${ }^{1}$, M. C. Simon ${ }^{1}$ W. Zamore ${ }^{2}$, D. Brugge ${ }^{3}$ and J. L. Durant ${ }^{*}$

${ }^{1}$ Department of Civil and Environmental Engineering, Tufts University, Medford, MA, USA.

${ }^{2}$ Somerville Transportation Equity Partnership, Somerville, MA, USA.

${ }^{3}$ Department of Public Health and Community Medicine, Tufts University, Boston, MA, USA.

${ }^{*}$ Corresponding Authors

Anderson Hall, Tufts University, Medford, MA 02155, USA, Tel: 617.627.5489, Fax: 617.627.3994, Email: john.durant@tufts.edu

Number of Pages: 29

Number of Tables: 6

Number of Figures: 17 


\section{Information Related to Flight Activity at Logan International Airport}

\section{Diurnal Flight Activity Patterns}

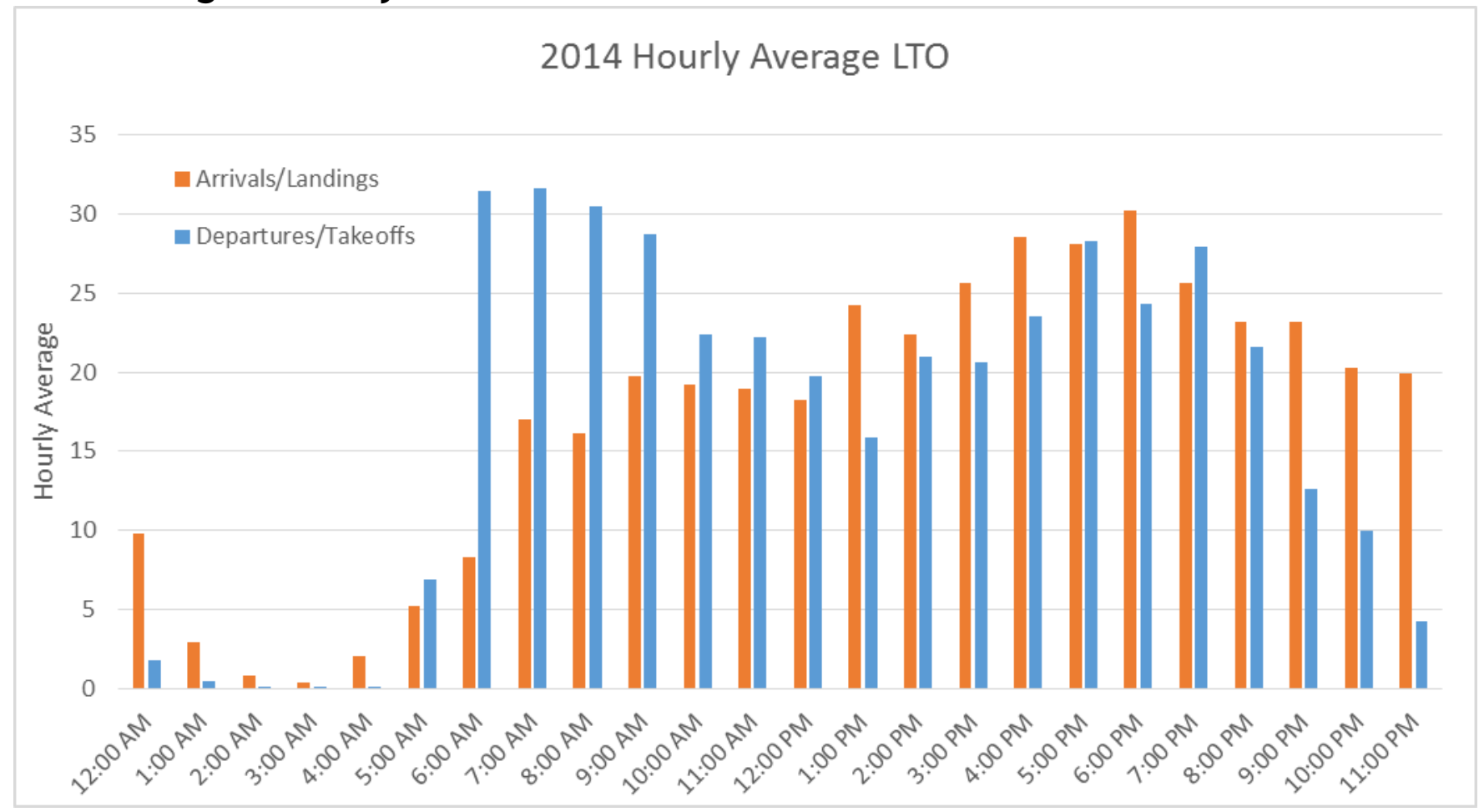

Figure S1: Annual (2014) average of hourly totals for landings and takeoffs through the day

Based on flight activity patterns, we classified the hours 0600-2359 as high and the hours 0000-0559 as low flight activity hours (see Figure S1). During the study period (Jan 2012-Aug 2015), the average LTO during high and low activity hours were $46.2 \pm 10.4 \mathrm{~h}^{-1}$ and $5.0 \pm 5.3 \mathrm{~h}^{-1}$, respectively. Arrivals and departures during these periods were $22.8 \pm 4.4 \mathrm{~h}^{-1}$ and $23.4 \pm 8.0 \mathrm{~h}^{-1}$, and $3.4 \pm 3.4 \mathrm{~h}^{-1}$ and $1.7 \pm 2.8 \mathrm{~h}^{-1}$, respectively. Traffic activity has a similar diurnal pattern but the difference between high and low activity was less: i.e., traffic during low activity period was about a quarter to a third of that in high activity period. The average hourly volume on $1-93$ and I-90, two major interstate highways in the area, during high and low activity periods were $8300 \pm 1700 \mathrm{~h}^{-1}$ and $5600 \pm 1400 \mathrm{~h}^{-1}$, and $2300 \pm 1700 \mathrm{~h}^{-1}$ and $1300 \pm 800 \mathrm{~h}^{-1}$, respectively. 


\section{Flight Statistics by Runway}

Table S1: Arrivals and Departure fractions on runways for 8 wind direction sectors

\begin{tabular}{|c|c|c|c|c|c|c|c|c|c|c|}
\hline \multirow[b]{2}{*}{ Runway } & \multirow{2}{*}{$\begin{array}{l}\text { Aircraft } \\
\text { Heading }\end{array}$} & \multicolumn{8}{|c|}{$\%$ of Arrivals by runway during Wind Direction* } & \multirow{2}{*}{$\begin{array}{c}\text { \% of Total Arrivals } \\
\text { January 2012-August } \\
2015\end{array}$} \\
\hline & & $\mathrm{N}$ & NE & $\mathrm{E}$ & SE & S & SW & W & NW & \\
\hline $22 R$ & 200 & $0 \%$ & $0 \%$ & $0 \%$ & $0 \%$ & $0 \%$ & $0 \%$ & $0 \%$ & $0 \%$ & $0 \%$ \\
\hline 04L & 20 & $10 \%$ & $12 \%$ & $19 \%$ & $16 \%$ & $1 \%$ & $0 \%$ & $1 \%$ & $4 \%$ & $7 \%$ \\
\hline $22 \mathrm{~L}$ & 200 & $2 \%$ & $2 \%$ & $4 \%$ & $17 \%$ & $53 \%$ & $50 \%$ & $18 \%$ & $3 \%$ & $21 \%$ \\
\hline 04R & 20 & $66 \%$ & $81 \%$ & $71 \%$ & $50 \%$ & $5 \%$ & $2 \%$ & $2 \%$ & $15 \%$ & $29 \%$ \\
\hline 27 & 257 & $7 \%$ & $1 \%$ & $1 \%$ & $10 \%$ & $36 \%$ & $42 \%$ & $51 \%$ & $31 \%$ & $27 \%$ \\
\hline 9 & 77 & $0 \%$ & $0 \%$ & $0 \%$ & $0 \%$ & $0 \%$ & $0 \%$ & $0 \%$ & $0 \%$ & $0 \%$ \\
\hline 32 & 306 & $1 \%$ & $0 \%$ & $0 \%$ & $0 \%$ & $0 \%$ & $0 \%$ & $3 \%$ & $5 \%$ & $1 \%$ \\
\hline 14 & 126 & $0 \%$ & $0 \%$ & $0 \%$ & $0 \%$ & $0 \%$ & $0 \%$ & $0 \%$ & $0 \%$ & $0 \%$ \\
\hline $33 R$ & 315 & $0 \%$ & $0 \%$ & $0 \%$ & $0 \%$ & $0 \%$ & $0 \%$ & $0 \%$ & $1 \%$ & $0 \%$ \\
\hline $15 \mathrm{~L}$ & 135 & $0 \%$ & $0 \%$ & $0 \%$ & $0 \%$ & $0 \%$ & $0 \%$ & $0 \%$ & $0 \%$ & $0 \%$ \\
\hline $33 \mathrm{~L}$ & 315 & $14 \%$ & $3 \%$ & $1 \%$ & $3 \%$ & $3 \%$ & $5 \%$ & $24 \%$ & $42 \%$ & $14 \%$ \\
\hline $15 R$ & 135 & $0 \%$ & $1 \%$ & $4 \%$ & $4 \%$ & $1 \%$ & $0 \%$ & $0 \%$ & $0 \%$ & $1 \%$ \\
\hline \multirow[t]{2}{*}{ Runway } & \multirow{2}{*}{$\begin{array}{l}\text { Aircraft } \\
\text { Heading }\end{array}$} & \multicolumn{8}{|c|}{$\begin{array}{l}\% \text { of Departures by runway during Wind } \\
\text { Direction* }\end{array}$} & $\begin{array}{l}\% \text { of Total Departures } \\
\text { January 2012-August }\end{array}$ \\
\hline & & $\mathrm{N}$ & $\mathrm{NE}$ & $E$ & SE & $\mathrm{S}$ & SW & W & NW & 2015 \\
\hline $22 R$ & 200 & $2 \%$ & $2 \%$ & $3 \%$ & $19 \%$ & $63 \%$ & $66 \%$ & $39 \%$ & $7 \%$ & $28 \%$ \\
\hline $04 \mathrm{~L}$ & 20 & $3 \%$ & $4 \%$ & $5 \%$ & $3 \%$ & $0 \%$ & $0 \%$ & $0 \%$ & $1 \%$ & $2 \%$ \\
\hline $22 \mathrm{~L}$ & 200 & $4 \%$ & $4 \%$ & $4 \%$ & $10 \%$ & $22 \%$ & $20 \%$ & $8 \%$ & $2 \%$ & $9 \%$ \\
\hline 04R & 20 & $12 \%$ & $10 \%$ & $8 \%$ & $7 \%$ & $3 \%$ & $2 \%$ & $1 \%$ & $5 \%$ & $5 \%$ \\
\hline 27 & 257 & $7 \%$ & $2 \%$ & $0 \%$ & $2 \%$ & $1 \%$ & $2 \%$ & $18 \%$ & $32 \%$ & $10 \%$ \\
\hline 9 & 77 & $61 \%$ & $76 \%$ & $76 \%$ & $55 \%$ & $5 \%$ & $1 \%$ & $2 \%$ & $13 \%$ & $29 \%$ \\
\hline 32 & 306 & $0 \%$ & $0 \%$ & $0 \%$ & $0 \%$ & $0 \%$ & $0 \%$ & $0 \%$ & $0 \%$ & $0 \%$ \\
\hline 14 & 126 & $0 \%$ & $0 \%$ & $0 \%$ & $0 \%$ & $0 \%$ & $0 \%$ & $0 \%$ & $0 \%$ & $0 \%$ \\
\hline $33 R$ & 315 & $2 \%$ & $2 \%$ & $2 \%$ & $1 \%$ & $0 \%$ & $0 \%$ & $0 \%$ & $1 \%$ & $1 \%$ \\
\hline $15 \mathrm{~L}$ & 135 & $0 \%$ & $0 \%$ & $0 \%$ & $0 \%$ & $1 \%$ & $1 \%$ & $1 \%$ & $0 \%$ & $0 \%$ \\
\hline $33 \mathrm{~L}$ & 315 & $7 \%$ & $1 \%$ & $0 \%$ & $1 \%$ & $0 \%$ & $2 \%$ & $21 \%$ & $32 \%$ & $10 \%$ \\
\hline $15 R$ & 135 & $2 \%$ & $1 \%$ & $1 \%$ & $1 \%$ & $4 \%$ & $5 \%$ & $10 \%$ & $8 \%$ & $5 \%$ \\
\hline
\end{tabular}

*Wind direction data was available for $98.8 \%$ of the flight activity during January 2012-August 2015. 


\section{Details of Monitoring Sites and Instruments}

Table S2: Details of monitoring sites and instruments used

\begin{tabular}{|c|c|c|c|}
\hline & Chelsea & Boston Globe & Roxbury \\
\hline CPC Model $^{1}$ & Model 3783 & Model 3775 & Model 3783 \\
\hline CPC d50, Accuracy & $7 \mathrm{~nm}, \pm 10 \%$ & $\begin{array}{c}4 \mathrm{~nm}, \pm 10 \% \text { for } \\
<50000 \text { and } \\
\pm 20 \% \text { for } \\
>50000\end{array}$ & $7 \mathrm{~nm}, \pm 10 \%$ \\
\hline CPC detectable maximum concentration & $10^{6}$ particles $/ \mathrm{cm}^{3}$ & $\begin{array}{c}50000,10^{7} \\
\text { particles } / \mathrm{cm}^{3}\end{array}$ & $10^{6}$ particles $/ \mathrm{cm}^{3}$ \\
\hline Monitoring Period & Jan 2014-Aug 2015 & Mar-May 2011 & $\begin{array}{c}\text { Jan 2012-Aug } \\
2015\end{array}$ \\
\hline Location Coordinates & $42.396,-71.033$ & $\begin{array}{c}42.315,- \\
71.049\end{array}$ & $42.329,-71.083$ \\
\hline Distance, Azimuth Angle to Logan ${ }^{2}$ & $4 \mathrm{~km}, 151^{\circ}$ & $6.5 \mathrm{~km}, 30^{\circ}$ & $7.3 \mathrm{~km}, 56^{\circ}$ \\
\hline Impact Sectors & $130-175^{0}$ & $15-60^{0}$ & $45-65^{0}$ \\
\hline Annual Occurrence of Impact Sector Winds in 2014 & $5.3 \%$ & $7.5 \%$ & $3.60 \%$ \\
\hline
\end{tabular}

Table S3: Monitoring Instrumentation and Equipment used at Dudley Square, Roxbury EPA-STN Site

\begin{tabular}{|l|l|}
\hline PM2.5 AQI \& Speciation Mass & BAM-1020 W/PM2.5 SCC-Beta Attenuation \\
\hline Black carbon PM2.5 STP & Magee Scientific AE22ER Aethalometer-Optical absorption \\
\hline Carbon monoxide & Gas Filter Correlation Teledyne API 300 EU \\
\hline $\begin{array}{l}\text { Nitric oxide (NO), Nitrogen dioxide } \\
\text { (NO2), Oxides of nitrogen (NOx) }\end{array}$ & Chemiluminescence Teledyne API 200 EU/501 \\
\hline Sulfur dioxide & Ultraviolet Fluorescence API 100 EU \\
\hline Solar radiation & Met One Pyranometer Model 50.5 \\
\hline
\end{tabular}

CPCs were housed in locked, weatherproof, and temperature and humidity controlled boxes and conductive silicon tubing was used for sampling line. Sites were serviced weekly for data retrieval, and instrument time was reset to the National Institute of Standards and Technology official time (time.gov) during visits. During data processing all instrument-flagged data was reviewed and removed from the analysis. CPC were annually calibrated at factory. More than one machine and instrument model was used but side-by-side tests conducted in laboratory indicate good agreement (See Figure S2 below). Also, since not all data was concurrent we have refrained from spatial or siteto-site comparisons (that were also beyond the scope of this study). 


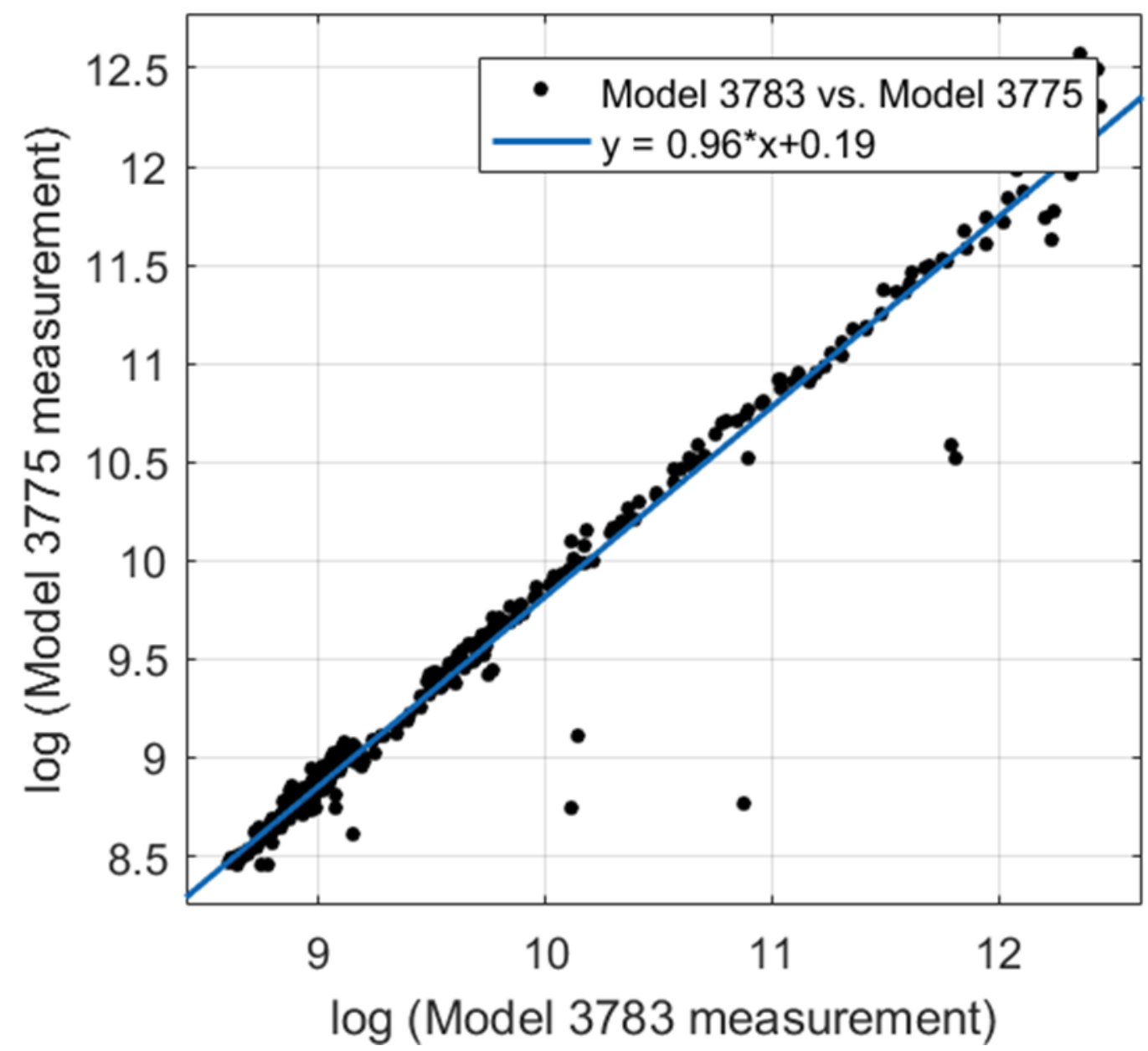

Figure S2: Comparison of laboratory measurements conducted with TSI CPC Models 3775 and 3783

Linear model:

Model $3775=\mathrm{p} 1{ }^{*}$ Model $3783+\mathrm{p} 2$

Coefficients (with 95\% confidence bounds):

$\mathrm{p} 1=0.9624(0.9447,0.9801)$

$\mathrm{p} 2=0.194(0.0224,0.3656)$

Goodness of fit:

SSE: 9.787

R-square: 0.9721

Adjusted R-square: 0.9721

RMSE: 0.1727 


\section{Rose diagrams for wind during monitoring periods at three sites}

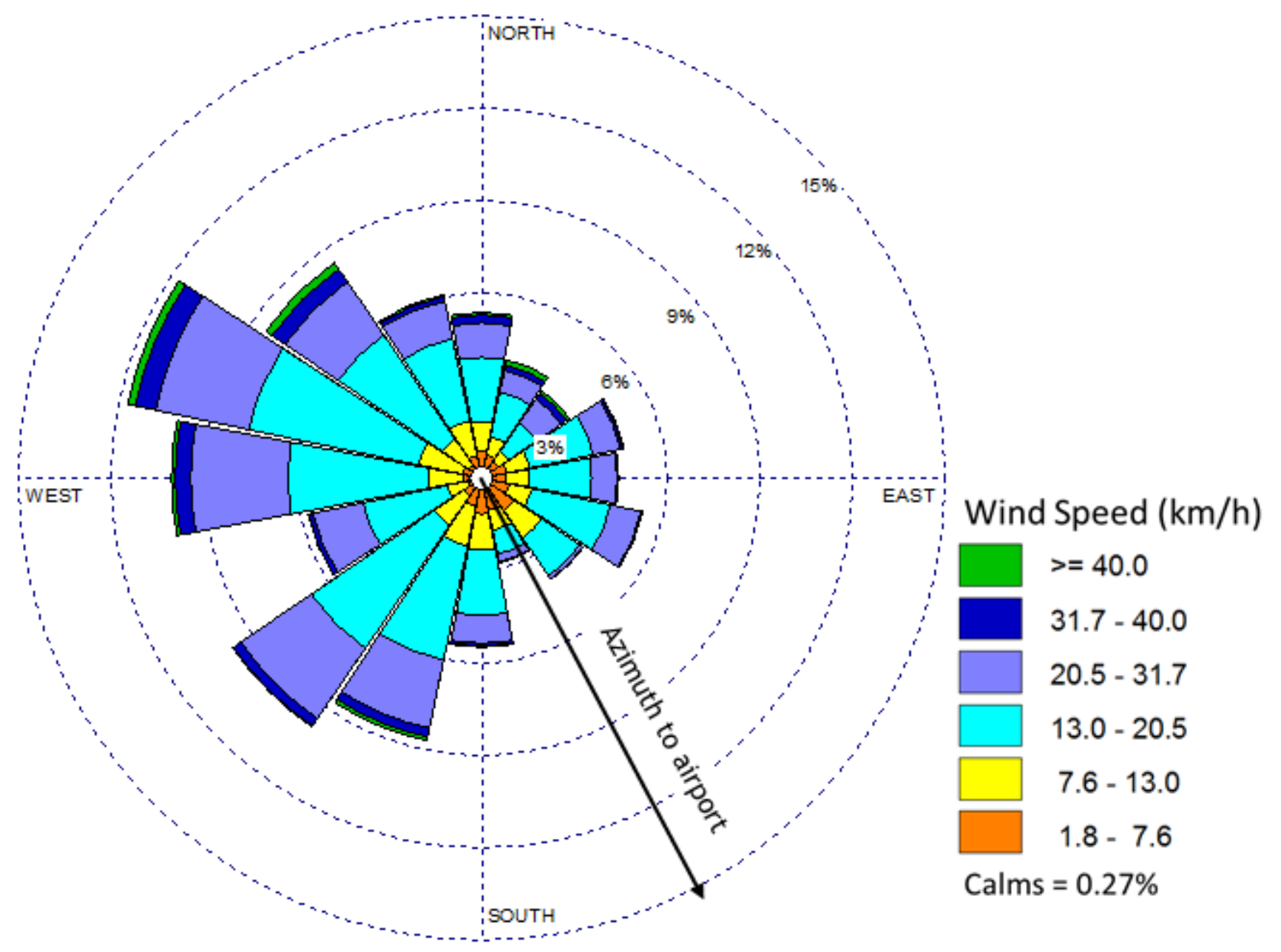

Figure S3 (a): Rose diagram for Jan 2014 - Aug 2015, i.e., the monitoring period for Chelsea site. Rose is based on 1-minue data reported by National Weather Service Automated Surface Station located at the airport. 


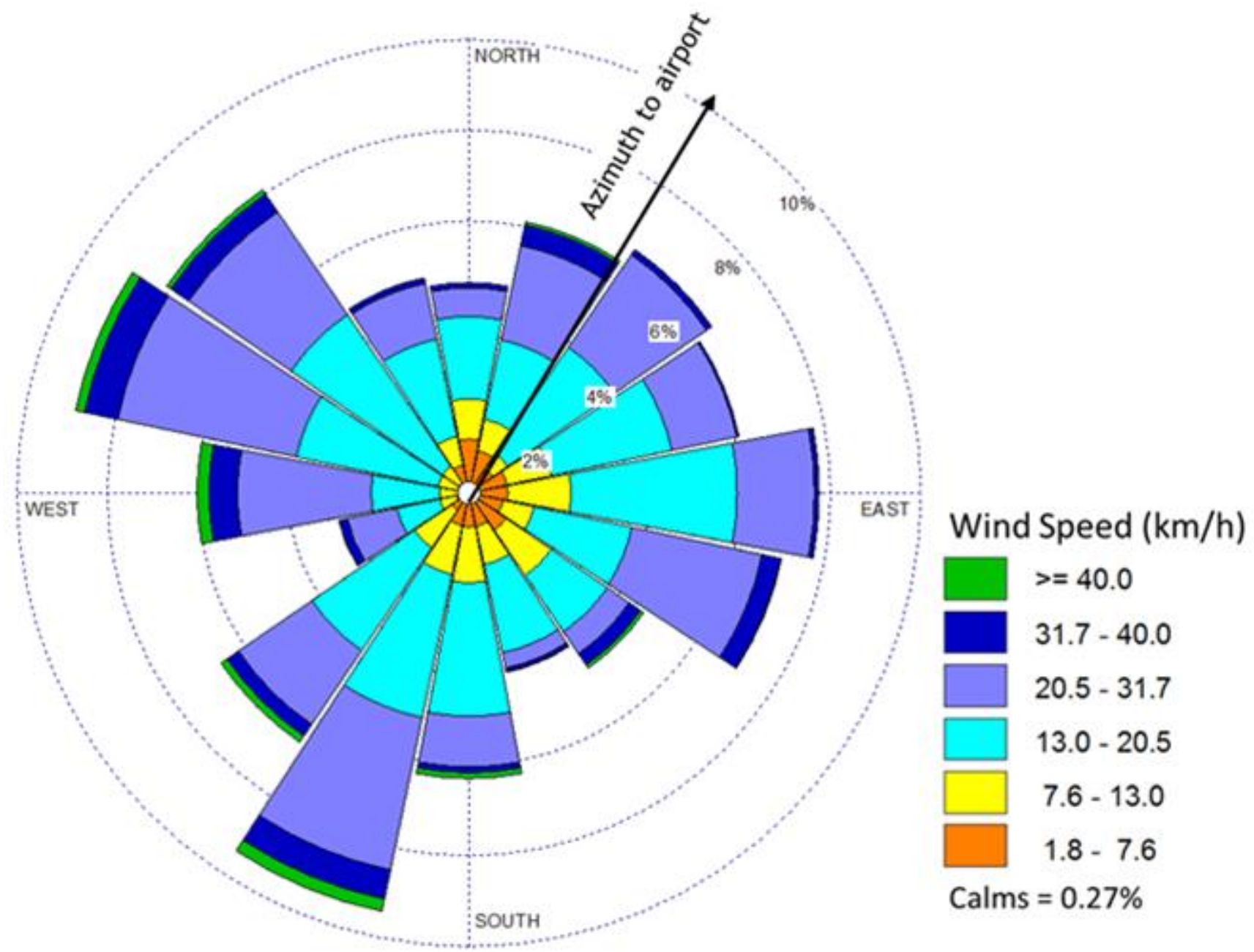

Figure S3 (b): Rose diagram for Mar 2011 - May 2011, i.e., the monitoring period for Boston Globe site. Rose is based on 1-minute data reported by National Weather Service Automated Surface Station located at the airport. 


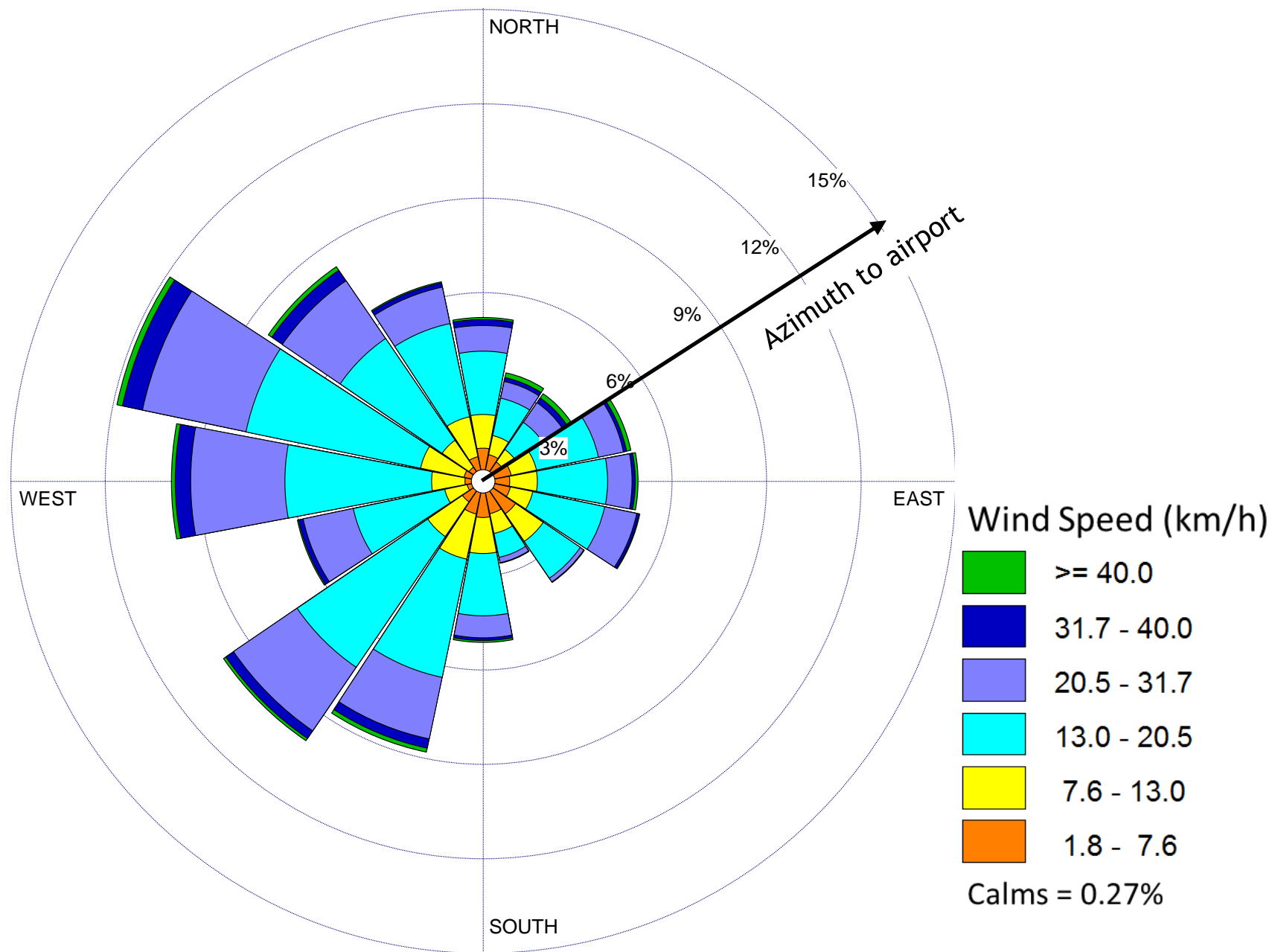

Figure S3 (c): Rose diagram for Jan 2012 - Aug 2015, i.e., the monitoring period for Roxbury site. Rose is based on 1-minute data reported by National Weather Service Automated Surface Station located at the airport. 


\section{Distribution of Particle Number and Other Pollutant Concentrations, and LTO}

- Hourly Average - Hourly Average Baselline

(a) Chelsea Site, Impact Sector

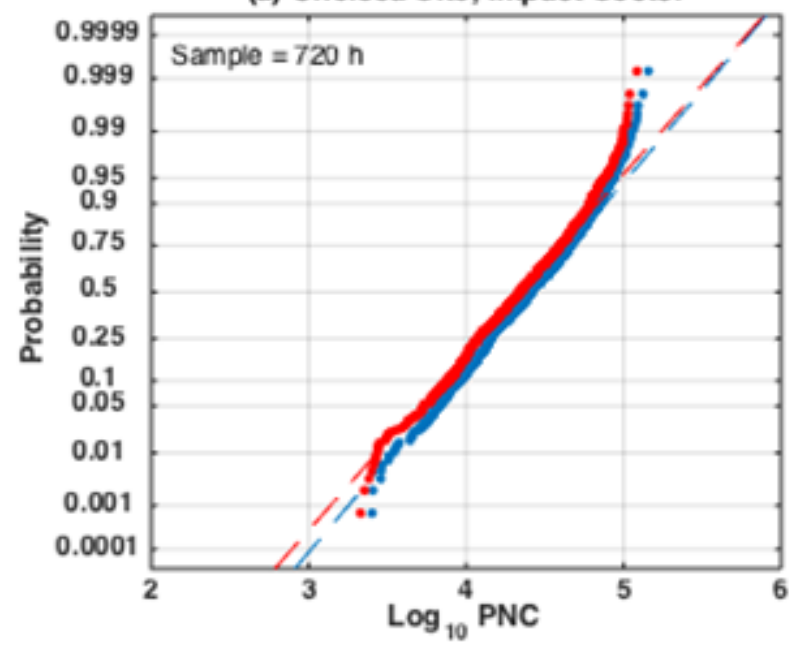

(c) Roxbury Site, Impact Sector

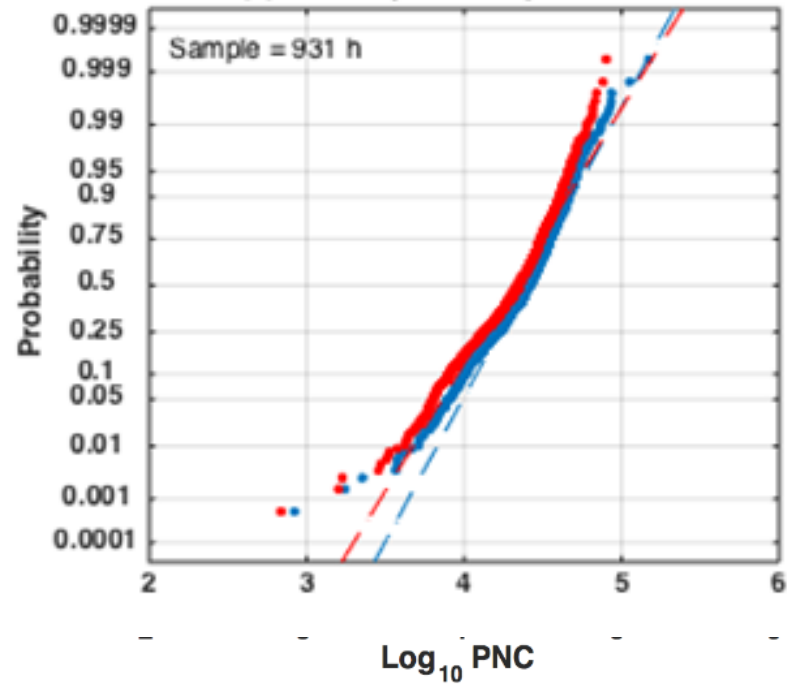

(b) Chelsea Site, All Sectors

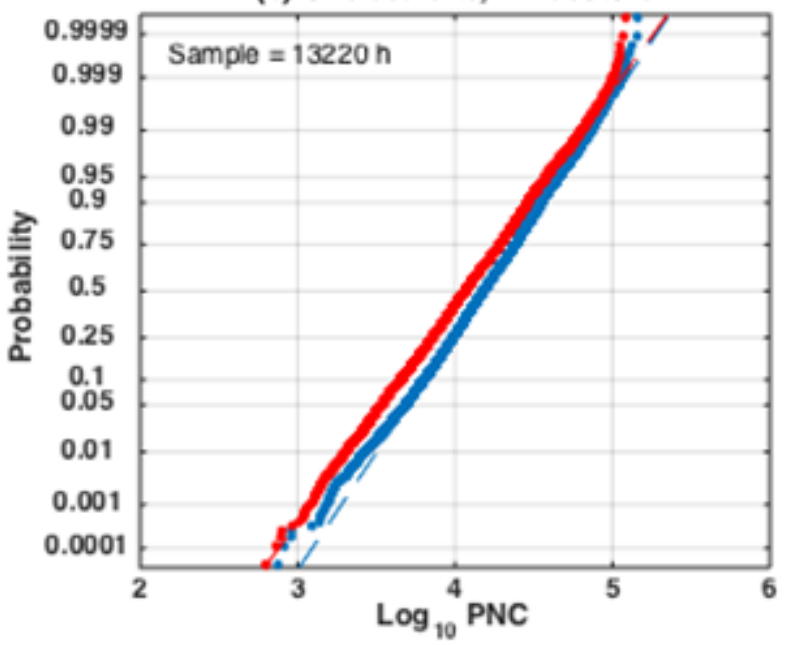

(d) Roxbury Site, All Sectors

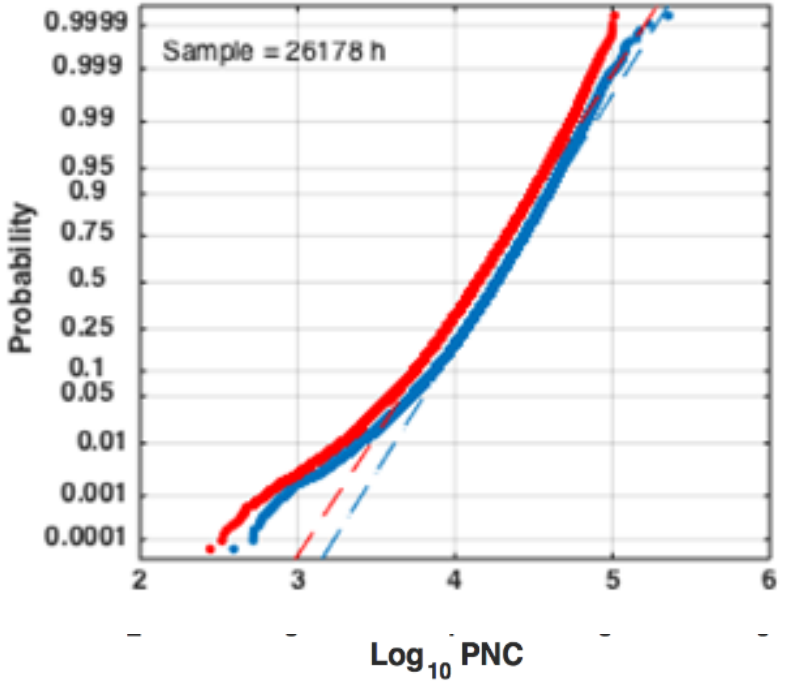

Figure S4 (a)-(d): Distribution of log transformed PN concentrations at Chelsea and Roxbury sites during impact sector winds and the entire dataset. Reference lines for normal distributions are shown. 
(e) Probability plot for Normal distribution of LTO during study period at Chelsea Site

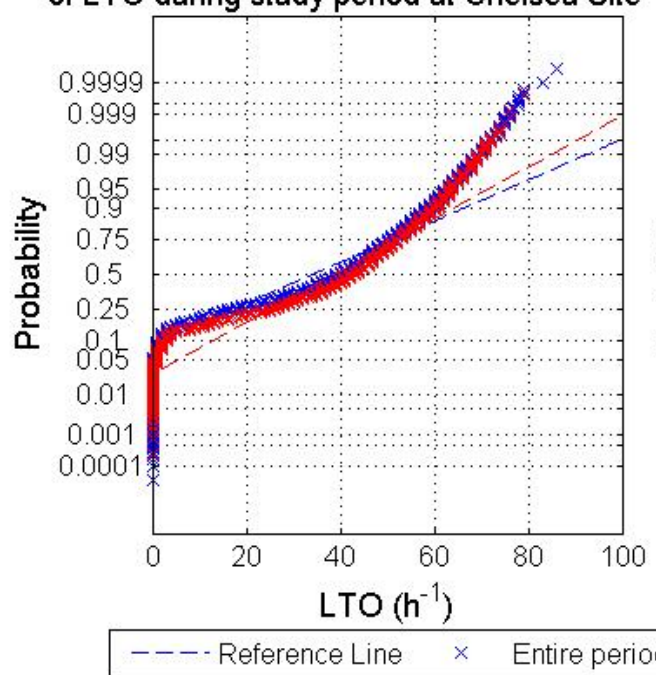

(f) Probability plot for Normal distribution LTO during study period at Roxbury Site

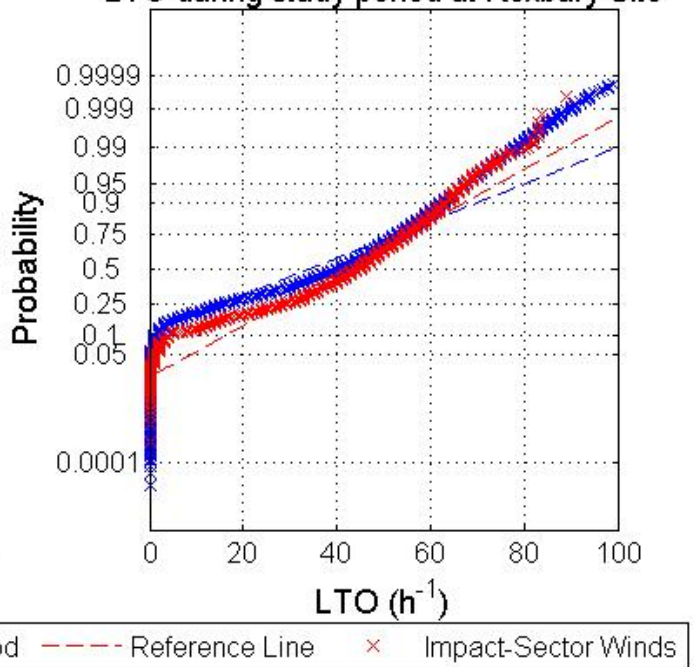

Figure S4 (e)-(f): Distribution of LTO during impact sector winds and the entire study periods at Chelsea and Roxbury sites. Reference lines for normal distributions are shown.

(g) Probability plot for Normal distribution of BC concentrations

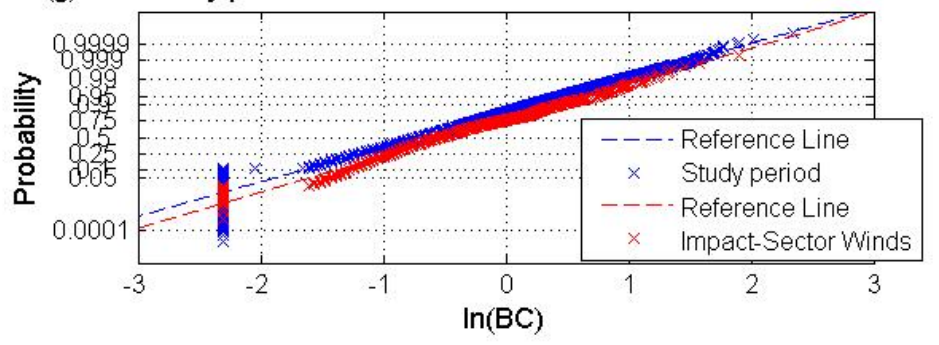

(h) Probability plot for Normal distribution of $\mathrm{CO}$ concentrations

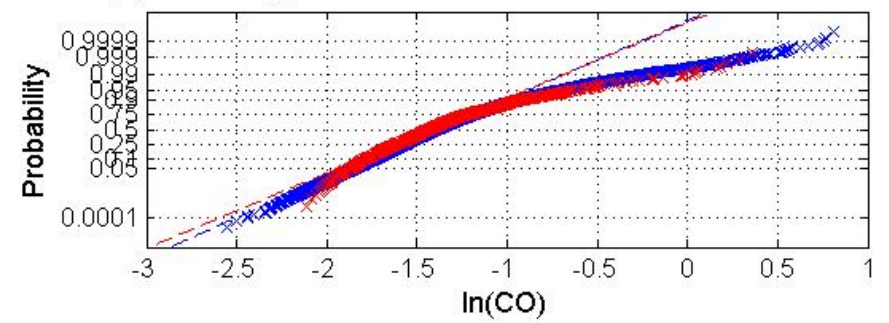

(i) Probability plot for Normal distribution of NOx concentrations

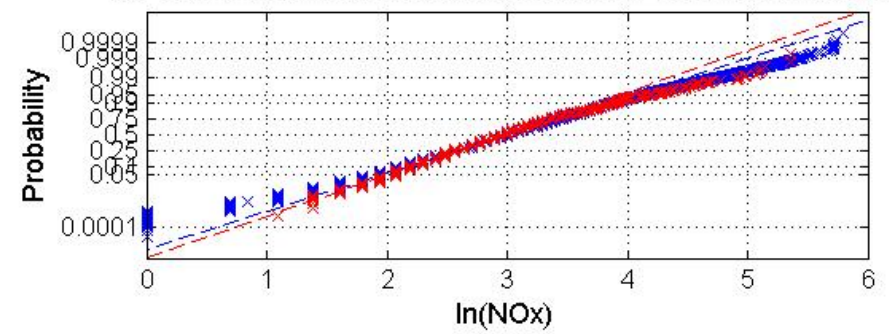

Figure S4 (g)-(i): Distribution of log-transformed concentrations of pollutants during impact sector winds and the entire study period at Roxbury site. Reference lines for normal distributions are shown. 


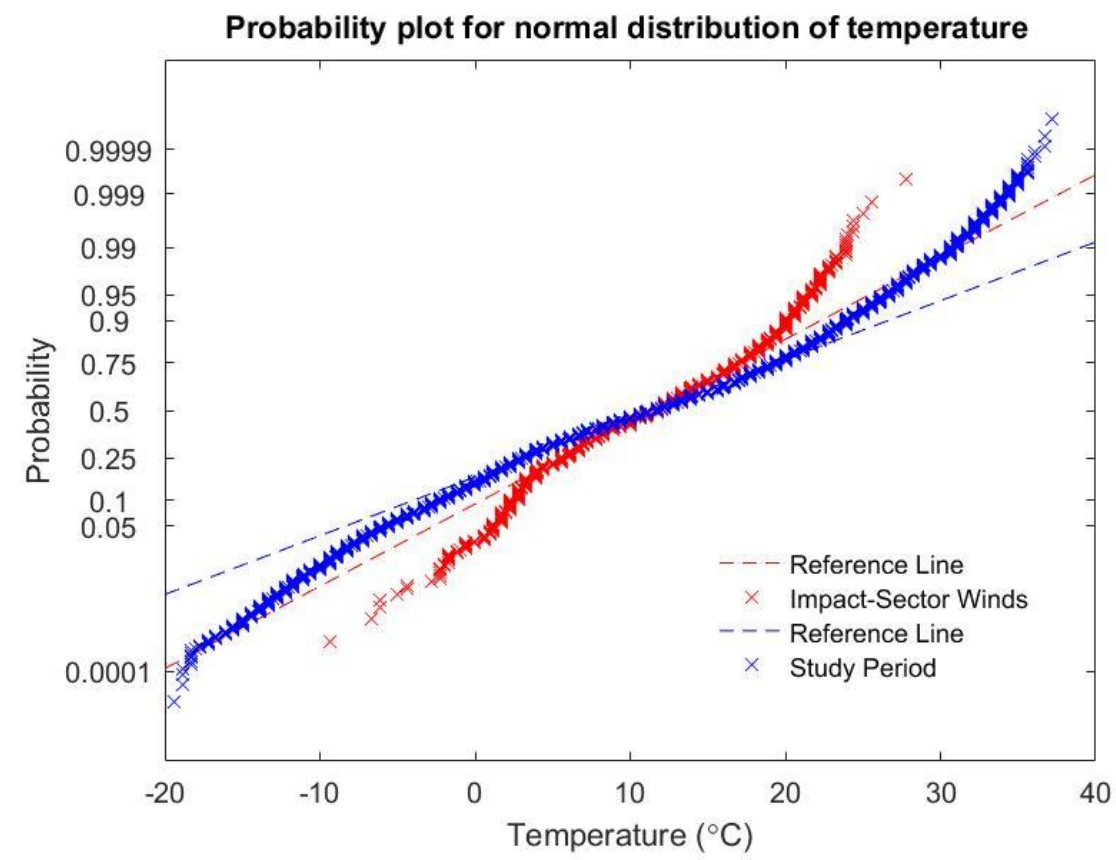

Figure S4 (j): Distribution of temperature during impact sector winds at Roxbury site and the entire study period. Reference lines for normal distributions are shown.

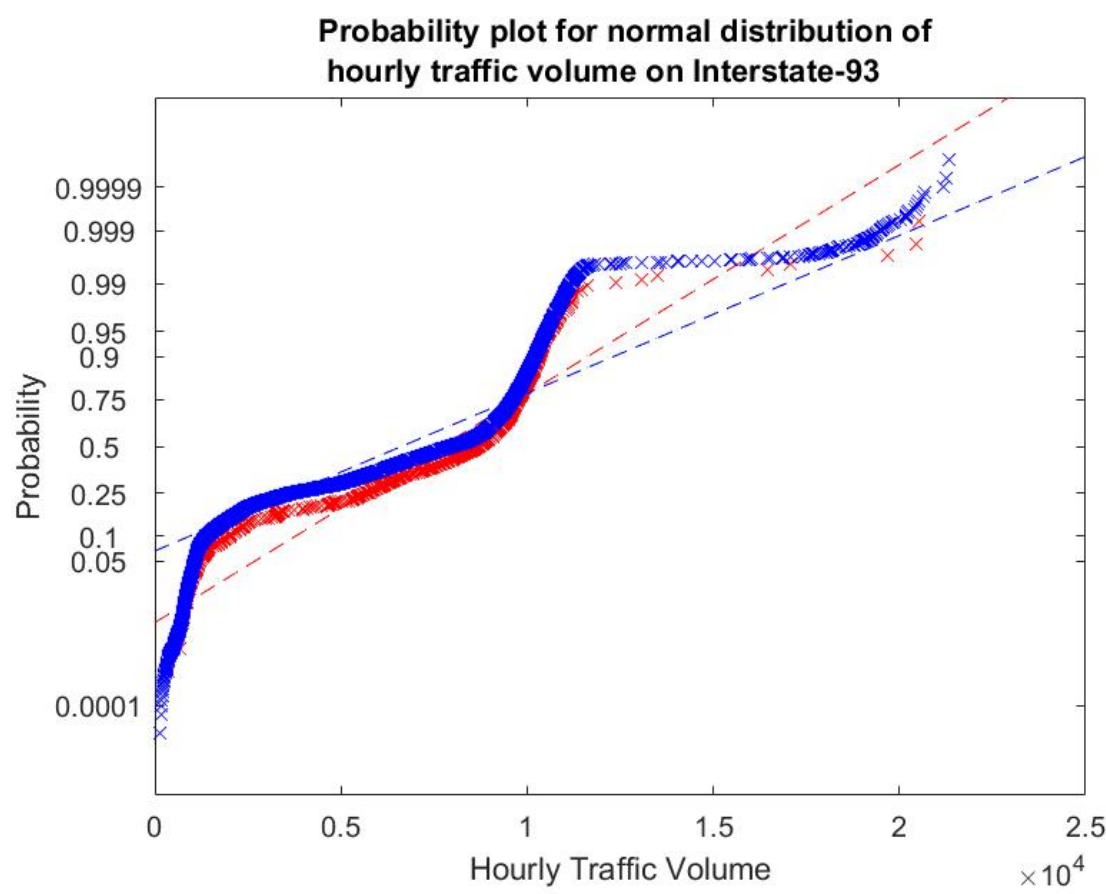

Figure S4 (k): Distribution of traffic volume on Interstate-93 during impact sector winds and the entire study period at Roxbury site. Reference lines for normal distributions are shown. 


\section{Traffic Volume Data and Fits}
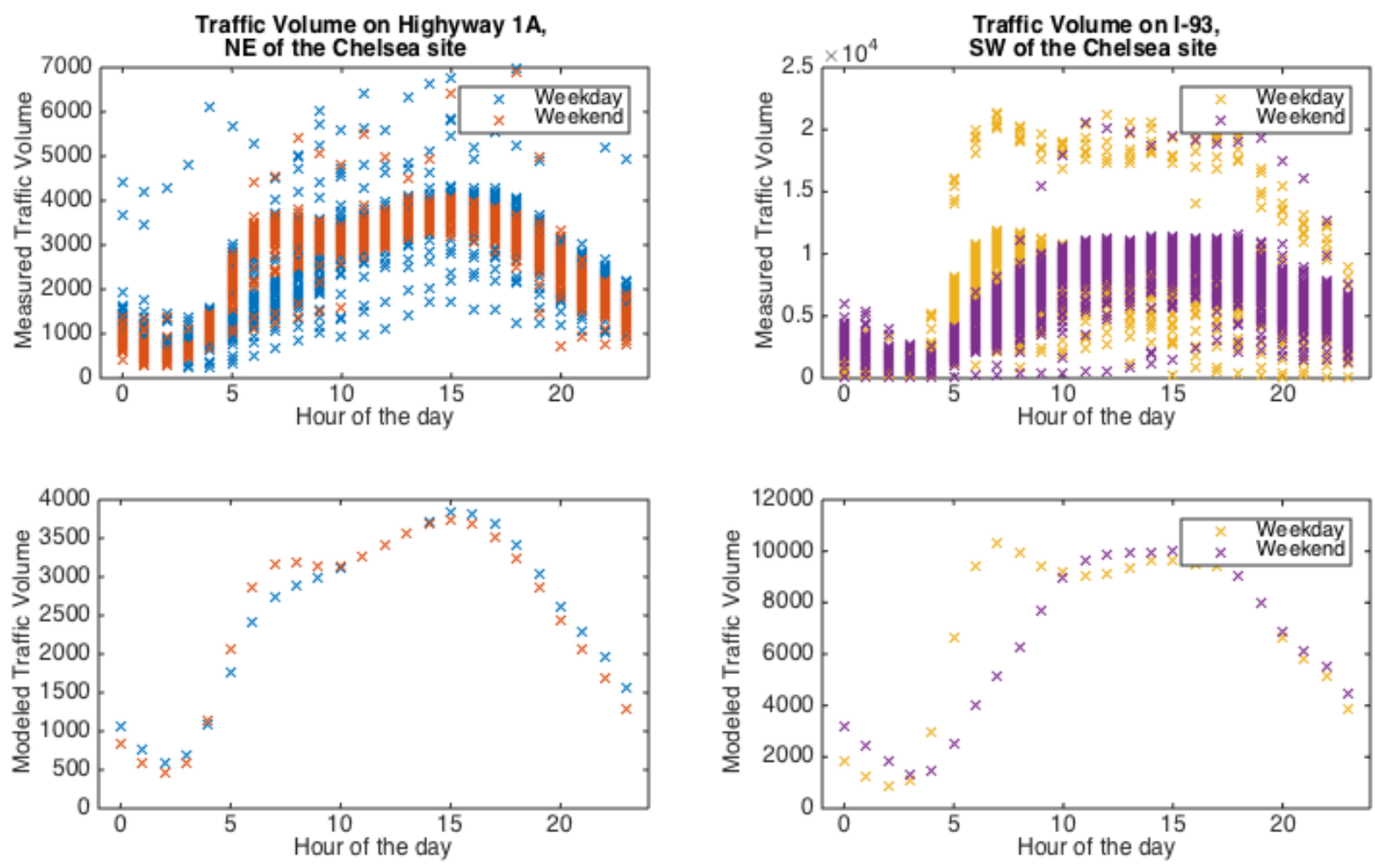

Figure S5 (a)-(d): Traffic volumes (measured and fitted) at a location on Highway 1A and I-93.

Traffic measurements at hourly resolution were available for 165 day at Lee Burbank Highway or Highway $1 \mathrm{~A}$ at station number 8087 during the January 2014 to August 2015 period monitoring period for Chelsea site. This monitor is located NE of the Chelsea site and north of the airport, and it was the closest traffic monitor to the Chelsea site with real time traffic measurements. Data was modeled using smoothing spline fit (using the curve fitting toolbox in Matlab) separately for weekday and weekend (shown in Figure S5) and modeled output was used to control for local traffic at Chelsea site. For comparison, data from station 8494 on I-93 (station located south of Downtown Boston) for January 2012 - August 2015 was similarly modeled. Goodness of fit statistics are presented in Table S4.

Table S4: Goodness of fit statistics for traffic volume on Highway 1A and I-93.

\begin{tabular}{|l|c|c|c|c|}
\hline \multicolumn{5}{|c|}{ Cubic spline goodness of fit statistics } \\
\hline & \multicolumn{2}{|c|}{ Highway 1A } & \multicolumn{2}{c|}{ Interstate-93 } \\
\hline & Weekdays & Weekend & Weekdays & Weekend \\
\hline SSE & $1.25 \mathrm{E}+09$ & $1.88 \mathrm{E}+08$ & $2.45 \mathrm{E}+10$ & $9.07 \mathrm{E}+09$ \\
\hline R-square & 0.79 & 0.90 & 0.89 & 0.88 \\
\hline dfe & $4.09 \mathrm{E}+03$ & $1.43 \mathrm{E}+03$ & $1.84 \mathrm{E}+04$ & $7.33 \mathrm{E}+03$ \\
\hline Adjusted r-square & 0.78 & 0.90 & 0.89 & 0.88 \\
\hline RMSE & 553.2393 & 363.4974 & $1.15 \mathrm{E}+03$ & $1.11 \mathrm{E}+03$ \\
\hline Number of Observations & 4104 & 1440 & 18464 & 7341 \\
\hline Smoothing parameter & 0.05 & 0.13 & 0.01 & 0.03 \\
\hline
\end{tabular}




\section{Additional Information related to PNC at stationary monitoring sites}

Table S5: Particle number concentrations at the three monitoring sites stratified by wind direction.

\begin{tabular}{|c|c|c|c|}
\hline & \multicolumn{3}{|c|}{ Site } \\
\hline & Chelsea & $\begin{array}{l}\text { Boston } \\
\text { Globe }\end{array}$ & Roxbury \\
\hline Impact sector & $130-175^{0}$ & $15-60^{0}$ & $45-65^{0}$ \\
\hline Annual (2014) occurrence of impact sector winds & $5.3 \%$ & $7.5 \%$ & $3.6 \%$ \\
\hline Other sources in impact sectors & $\begin{array}{c}\text { Interstate }(1.25 \mathrm{~km}), \\
\text { arterial roads, } \\
\text { shipping channel }\end{array}$ & $\begin{array}{l}\text { arterial } \\
\text { roads, dry- } \\
\text { dock }\end{array}$ & $\begin{array}{l}\text { highways }(0.5 \\
\& 1.5 \mathrm{~km}), \\
\text { arterial roads }\end{array}$ \\
\hline PNC during impact sector winds $\left(10^{3}\right.$ particles $\left./ \mathrm{cm}^{3}\right)$ & $n=641 \mathrm{~h}$ & $n=226 \mathrm{~h}$ & $n=1,051 \mathrm{~h}$ \\
\hline Mean Hourly Average Baseline (relative standard deviation) & $29( \pm 56 \%)$ & $20( \pm 119 \%)$ & $24( \pm 54 \%)$ \\
\hline Mean Hourly Average (relative standard deviation) & $34( \pm 75 \%)$ & $25( \pm 118 \%)$ & $28( \pm 54 \%)$ \\
\hline High Activity Hours (0600-2359) & $40( \pm 69 \%)$ & $32( \pm 103 \%)$ & $31( \pm 48 \%)$ \\
\hline Low Activity Hours (0000-0559) & $22( \pm 81 \%)$ & $10( \pm 118 \%)$ & $15( \pm 50 \%)$ \\
\hline Minimal to No Activity Hours (0100-0359) & $15( \pm 69 \%)$ & $9( \pm 154 \%)$ & $13( \pm 70 \%)$ \\
\hline PNC during wind other than from impact sectors $\left(10^{3}\right.$ particles $\left./ \mathrm{cm} 3\right)$ & $n=12,500 \mathrm{~h}$ & $n=939 \mathrm{~h}$ & $n=26,277 \mathrm{~h}$ \\
\hline Mean Hourly Average Baseline (relative standard deviation) & $14( \pm 76 \%)$ & $19( \pm 116 \%)$ & $16( \pm 67 \%)$ \\
\hline Mean Hourly Average (relative standard deviation) & $18( \pm 70 \%)$ & $31( \pm 109 \%)$ & $21( \pm 65 \%)$ \\
\hline High Activity Hours (0600-2359) & $19( \pm 68 \%)$ & $30( \pm 102 \%)$ & $23( \pm 60 \%)$ \\
\hline Low Activity Hours (0000-0559) & $14( \pm 71 \%)$ & $33( \pm 125 \%)$ & $14( \pm 67 \%)$ \\
\hline Minimal to No Activity Hours (0100-0359) & $13( \pm 69 \%)$ & $29( \pm 114 \%)$ & $12( \pm 62 \%)$ \\
\hline Closest major roadway, distance, direction & $\begin{array}{c}\text { Route } 1, \sim 300 \mathrm{~m}, \mathrm{SW}- \\
\mathrm{NW}\end{array}$ & $\begin{array}{l}\mathrm{I}-93, \sim 100 \\
\mathrm{~m}, \text { SSW- } \\
\text { NNW }\end{array}$ & $\begin{array}{c}\text { Route } 28, \sim 500 \\
\mathrm{~m}, \mathrm{~W}-\mathrm{NW}\end{array}$ \\
\hline PNC downwind of roadway $\left(10^{3}\right.$ particles $\left./ \mathrm{cm}^{3}\right)$ & $n=5,247 \mathrm{~h}$, in dataset & $\begin{array}{l}n=511 \mathrm{~h}, \text { in } \\
\text { dataset }\end{array}$ & $\begin{array}{l}n=7,544 \mathrm{~h}, \text { in } \\
\text { dataset }\end{array}$ \\
\hline Mean of Hourly Average Baseline (relative standard deviation) & $15( \pm 66 \%)$ & $26( \pm 102 \%)$ & $18( \pm 68 \%)$ \\
\hline Mean Hourly Average (relative standard deviation) & $19( \pm 61 \%)$ & $44( \pm 88 \%)$ & $25( \pm 64 \%)$ \\
\hline
\end{tabular}

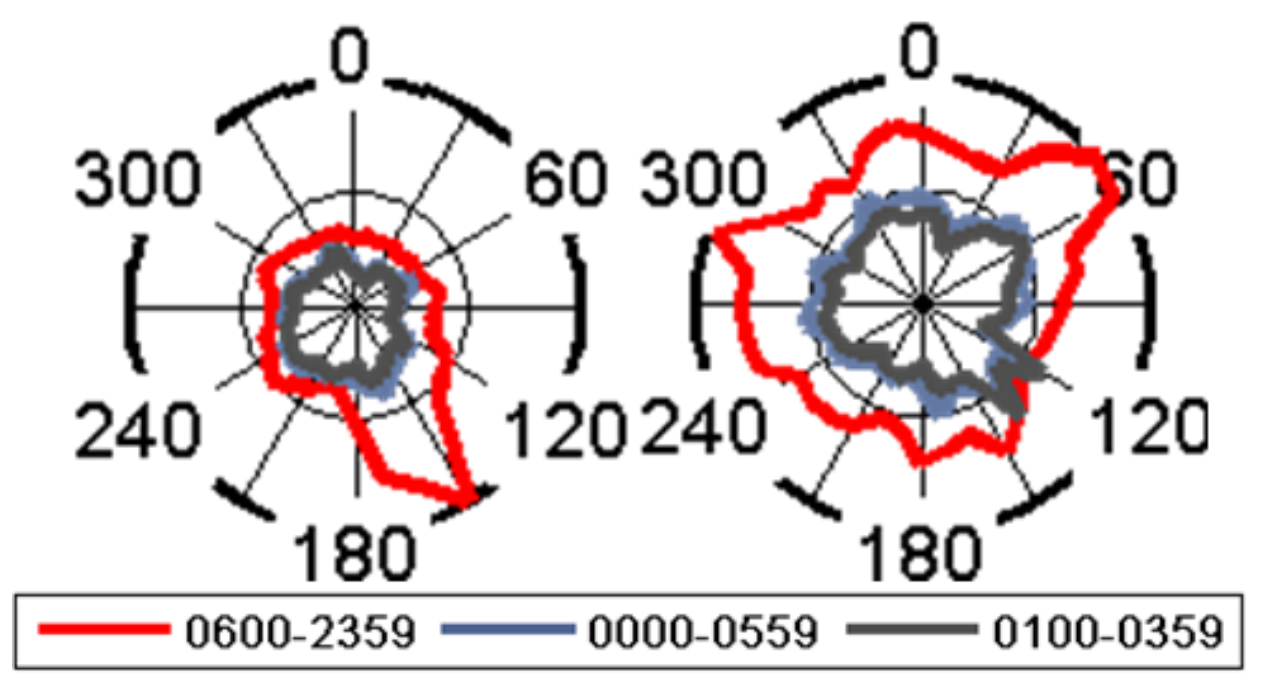

Figure S6: 2014 PNC roses for the Chelsea and Roxbury sites (normalized to the maximum) during high and low flight activity hours. 


\section{Chelsea Monitoring Site}
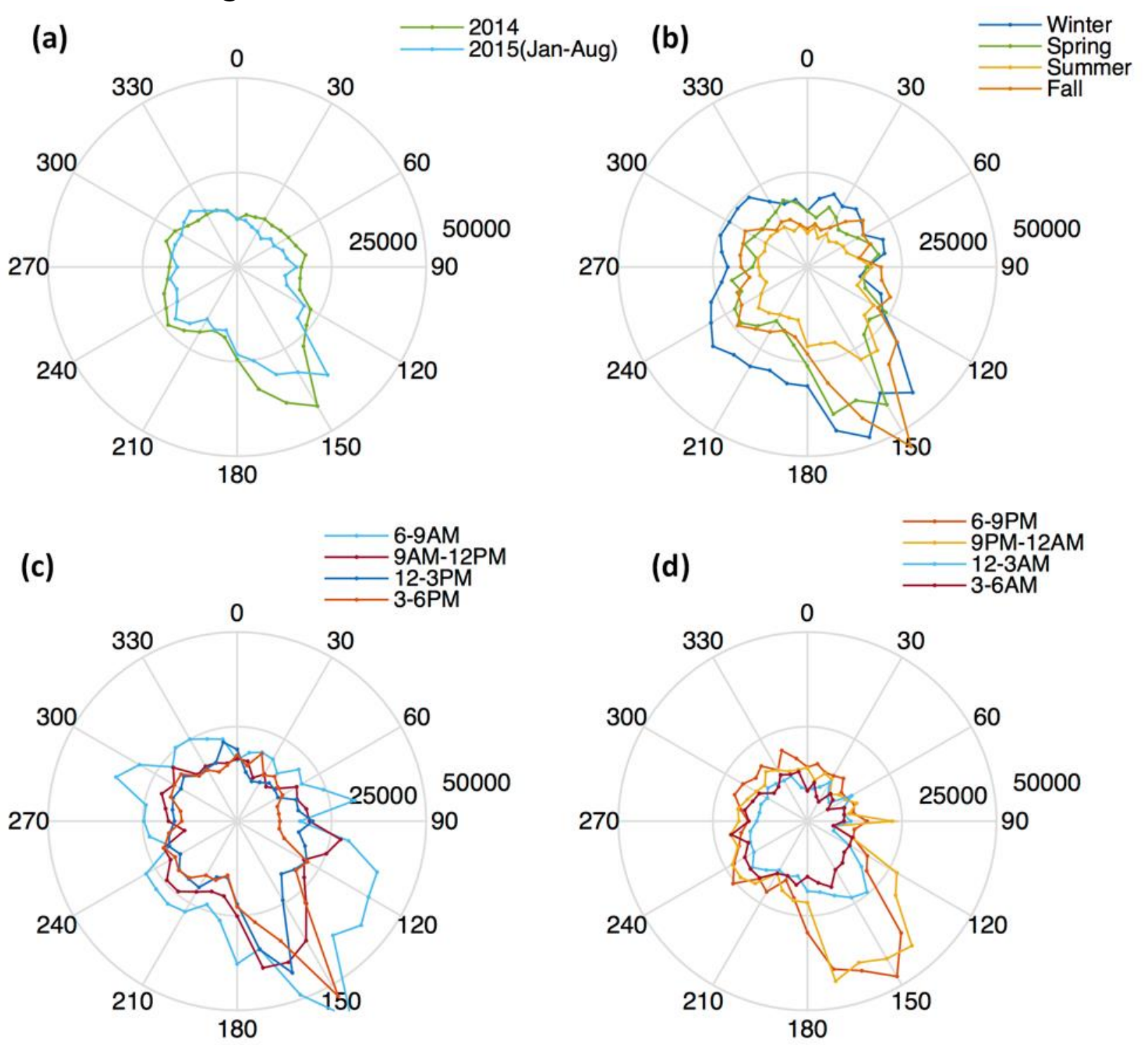


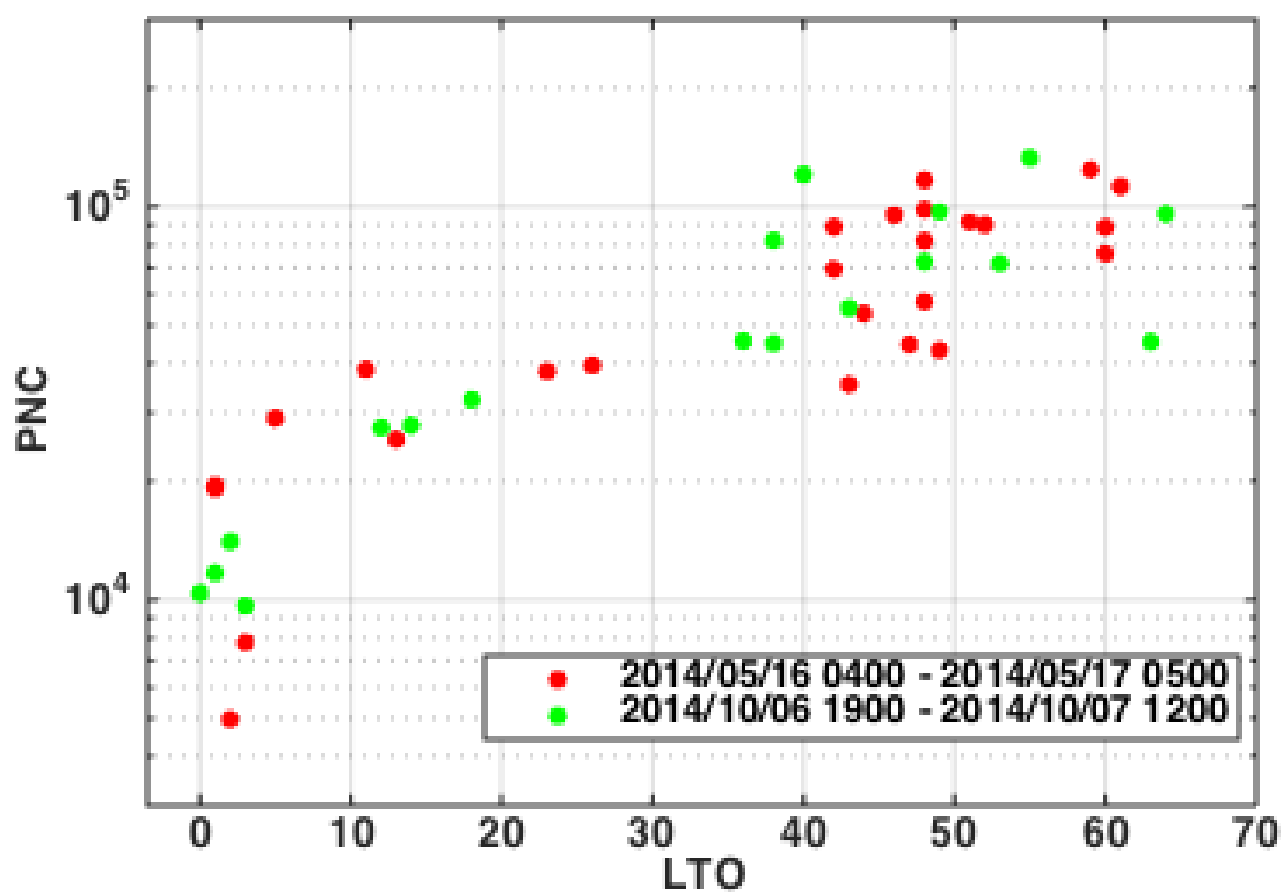

Figure S7 (e): Hourly average PNC vs LTO during the two longest, continuous periods of impact-sector winds at Chelsea site

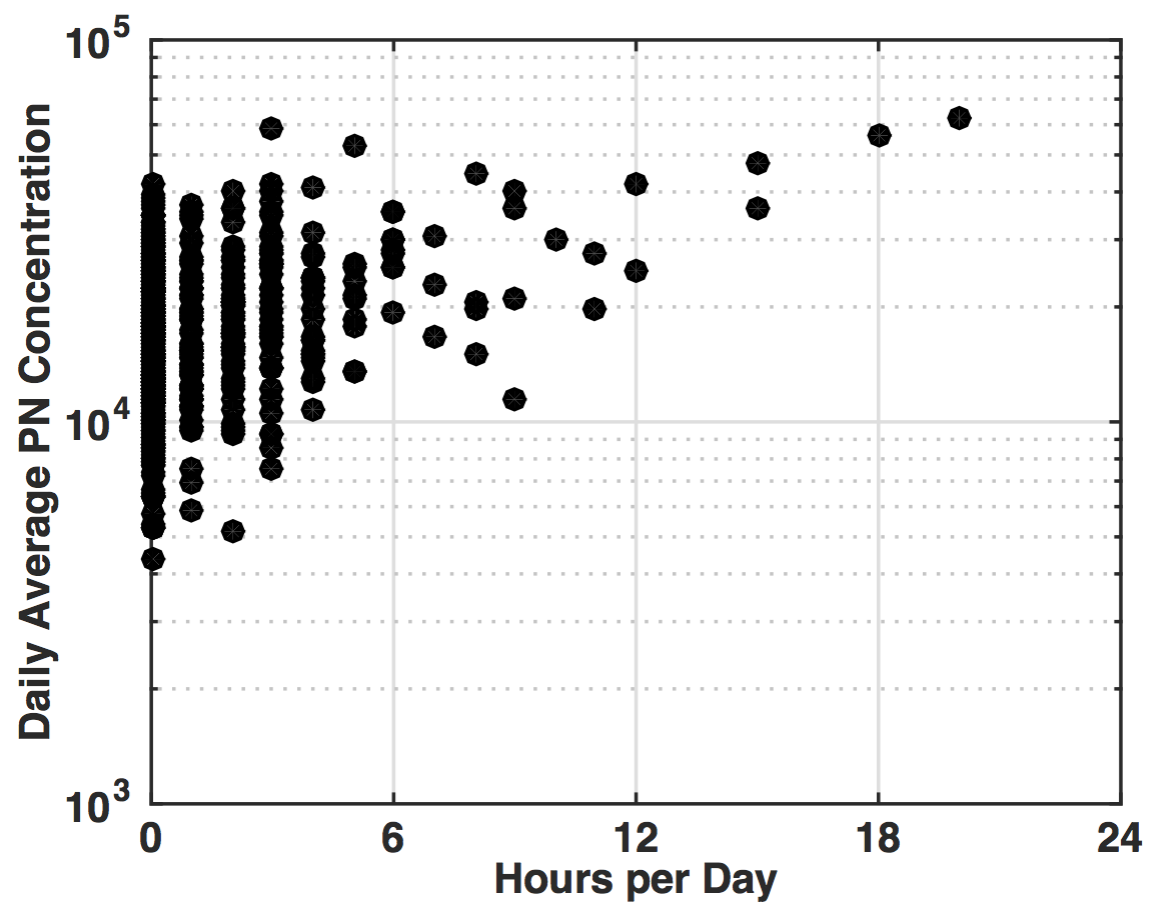

Figure S7 (f): Daily average PNC vs hours of impact-sector winds per day at Chelsea site 


\section{Boston Monitoring Site}

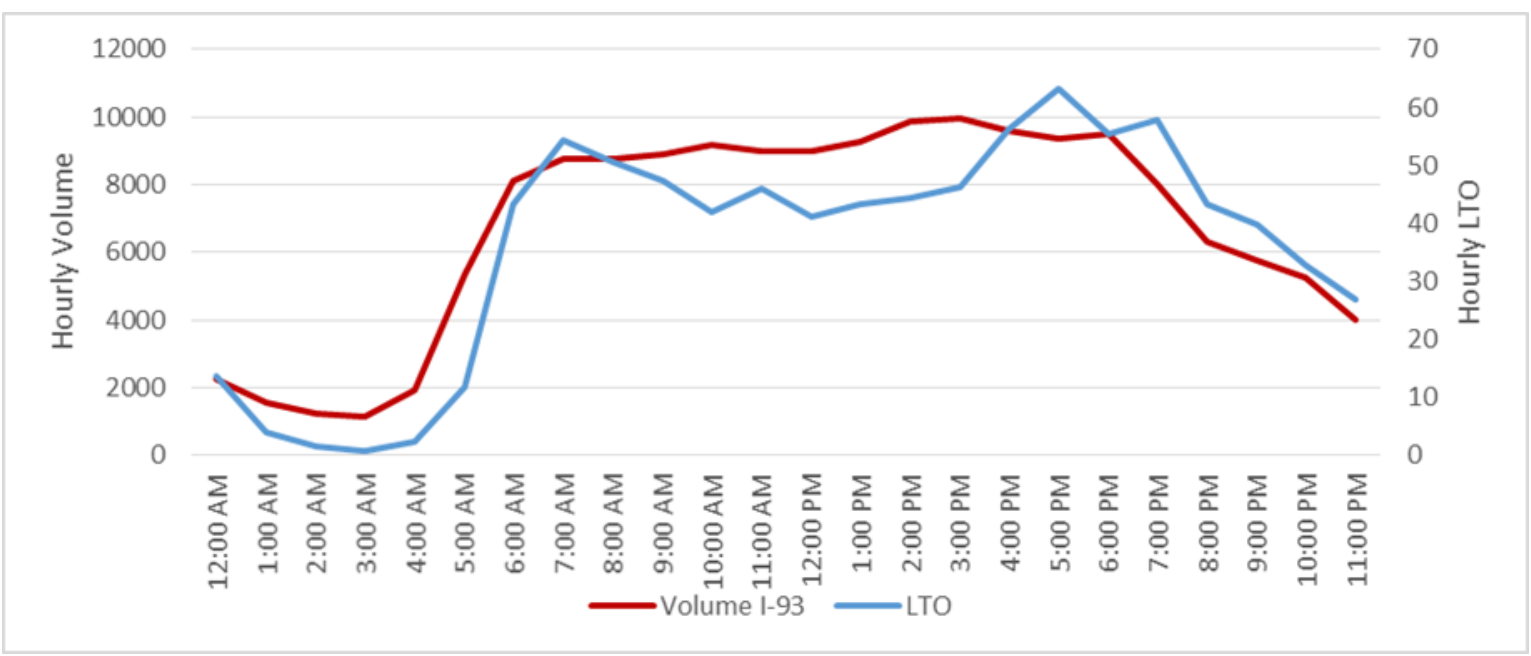

Figure S8 (a): Hourly average diurnal pattern of traffic volume on I-93 and flight operations (sum of landing and takeoffs) at Logan International Airport for the entire month May 2011.

\section{(b) Spearman rank correlation coefficient between PNC and Traffic Volume}

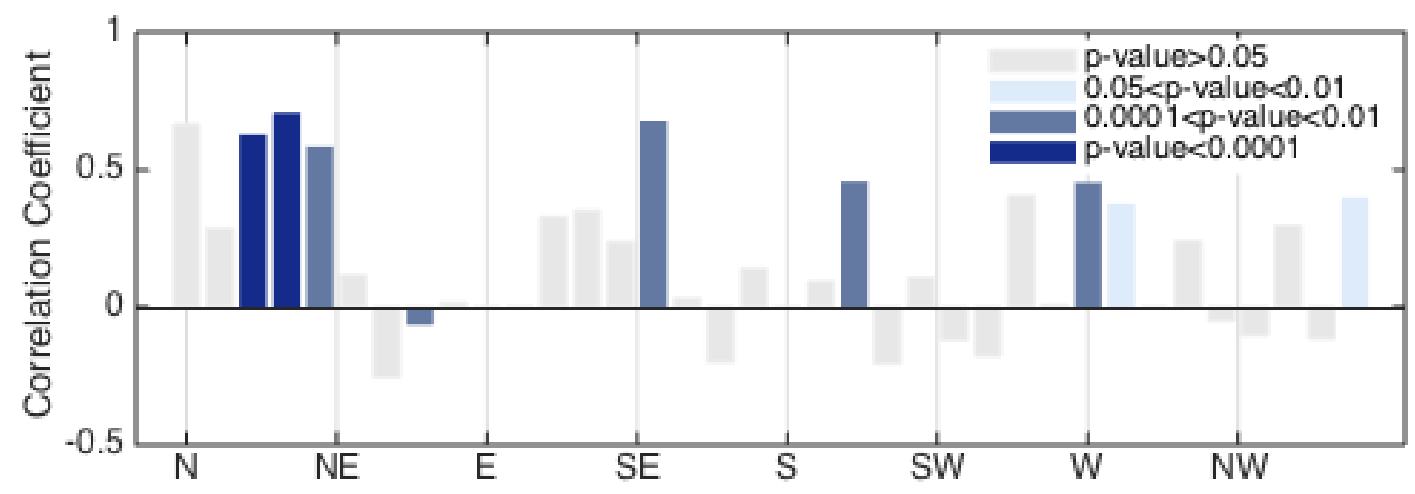

(c) Spearman rank correlation coefficient between PNC and LTO

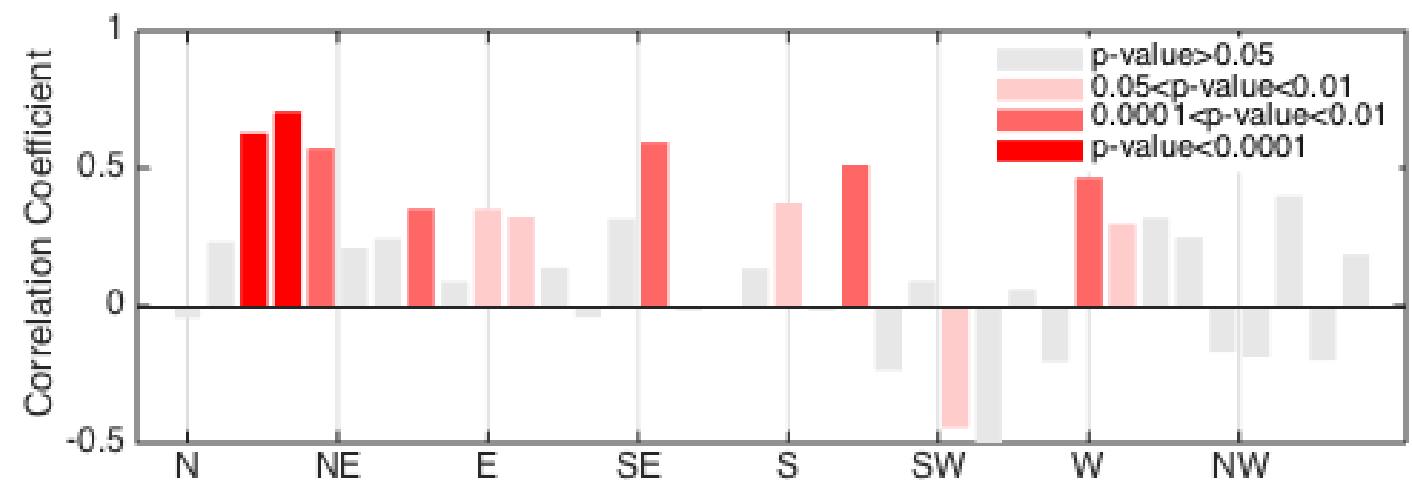

Figure S8 (b)-(c): Correlation coefficient between hourly average PNC measured at Boston Globe site and traffic volume on I-93, and PNC and LTO at the airport for all $3610^{\circ}$-wide-sectors. 


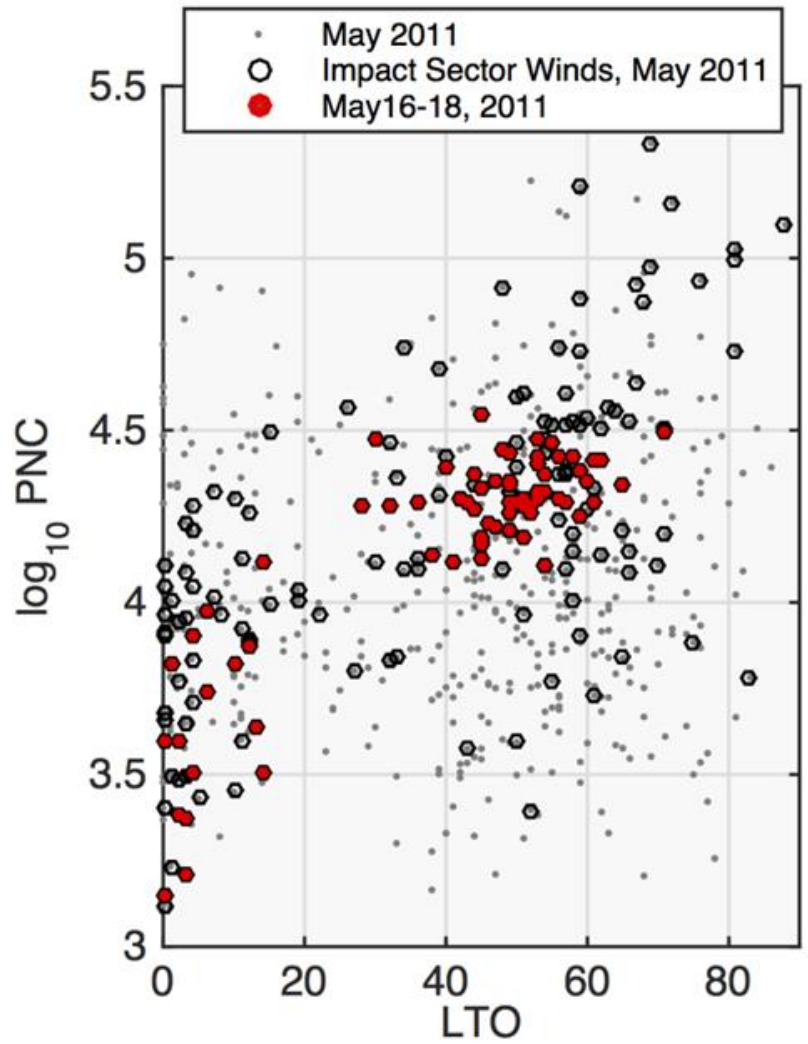

Figure S8 (d): May 2011 hourly average PNC plotted against LTO. The $72 \mathrm{~h}$ period (May 16-18) of continuous impact-sector winds is highlighted. 


\section{Roxbury Monitoring Site}
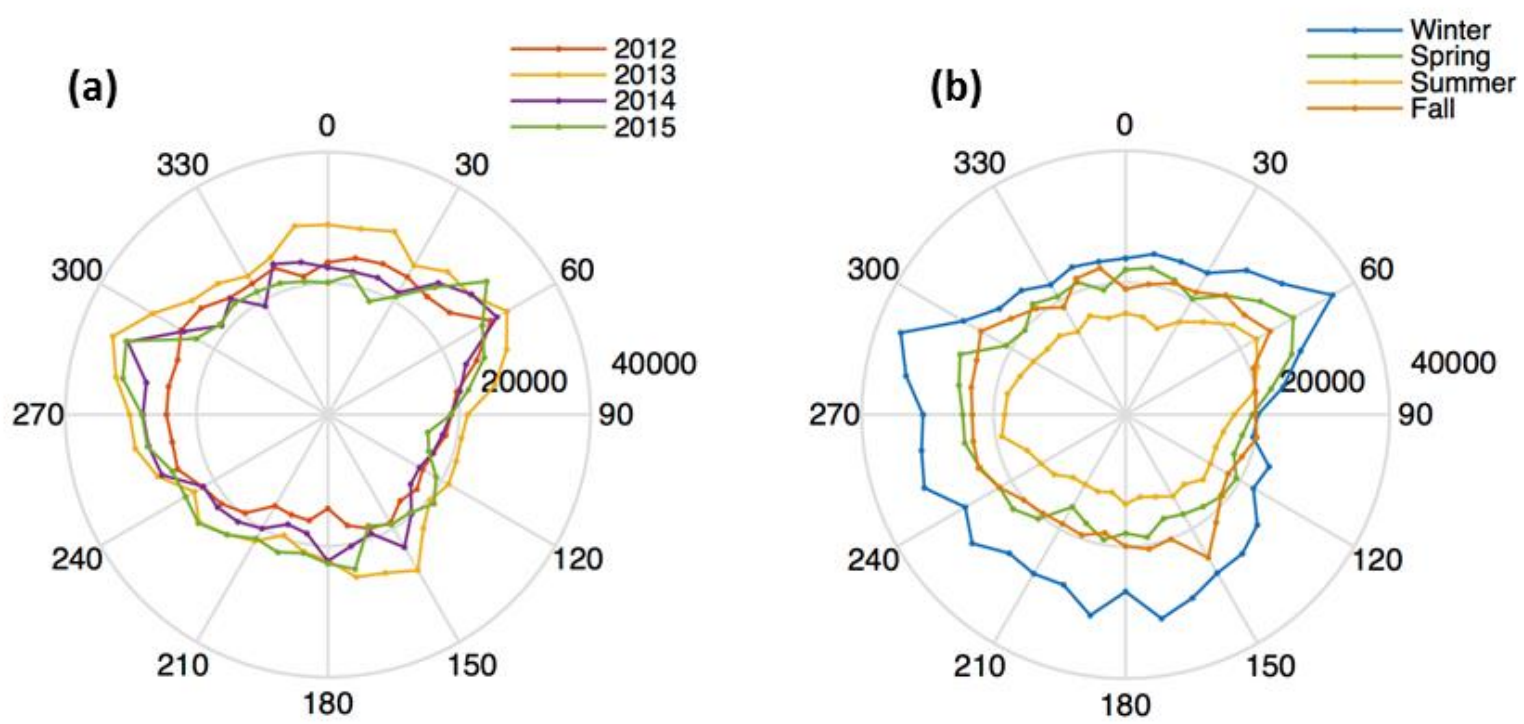

(c)

(d)
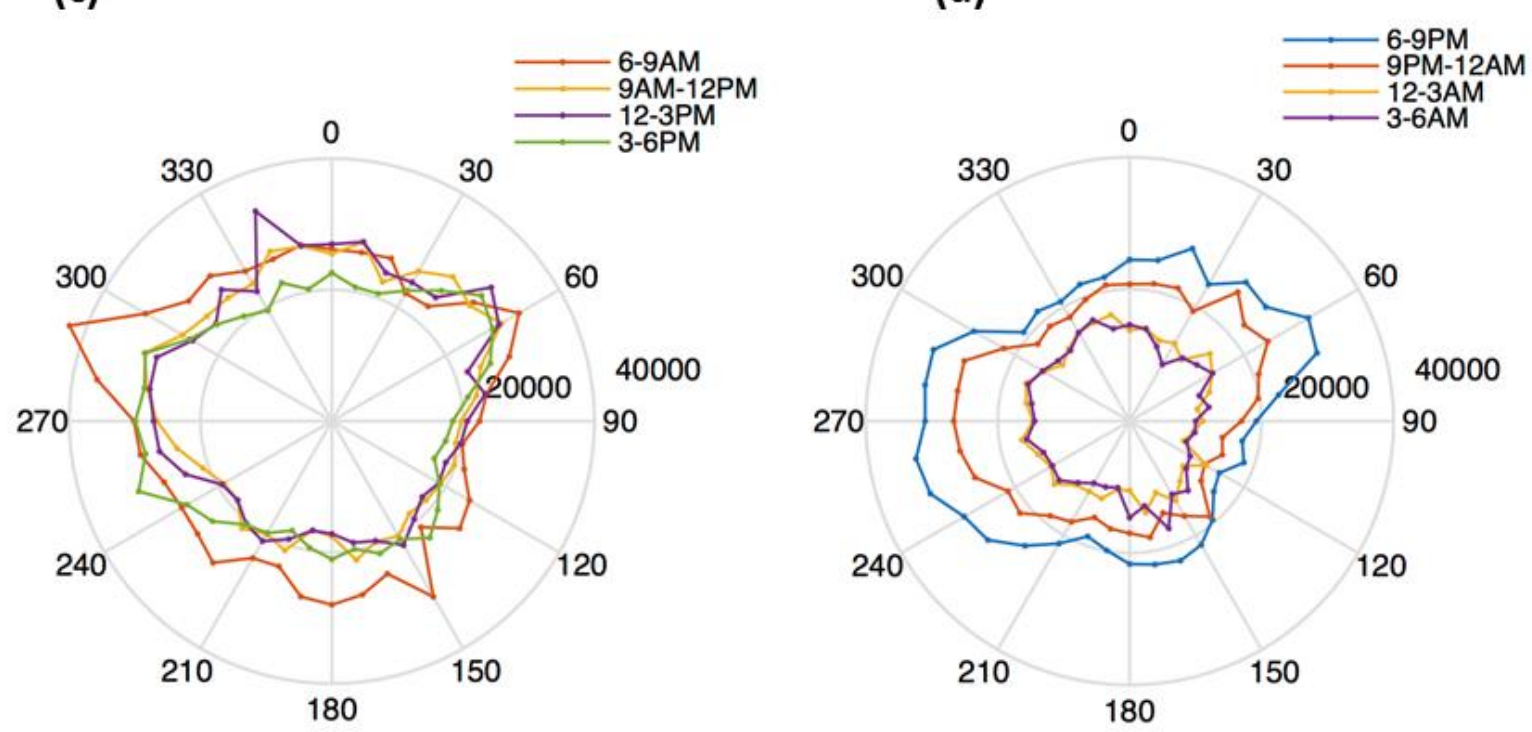

Figure S9 (a)-(d): $10^{\circ}$ wide sector average PNC at Roxbury for different years, seasons and time periods of the day during the monitoring period January 2012-August 2015. 


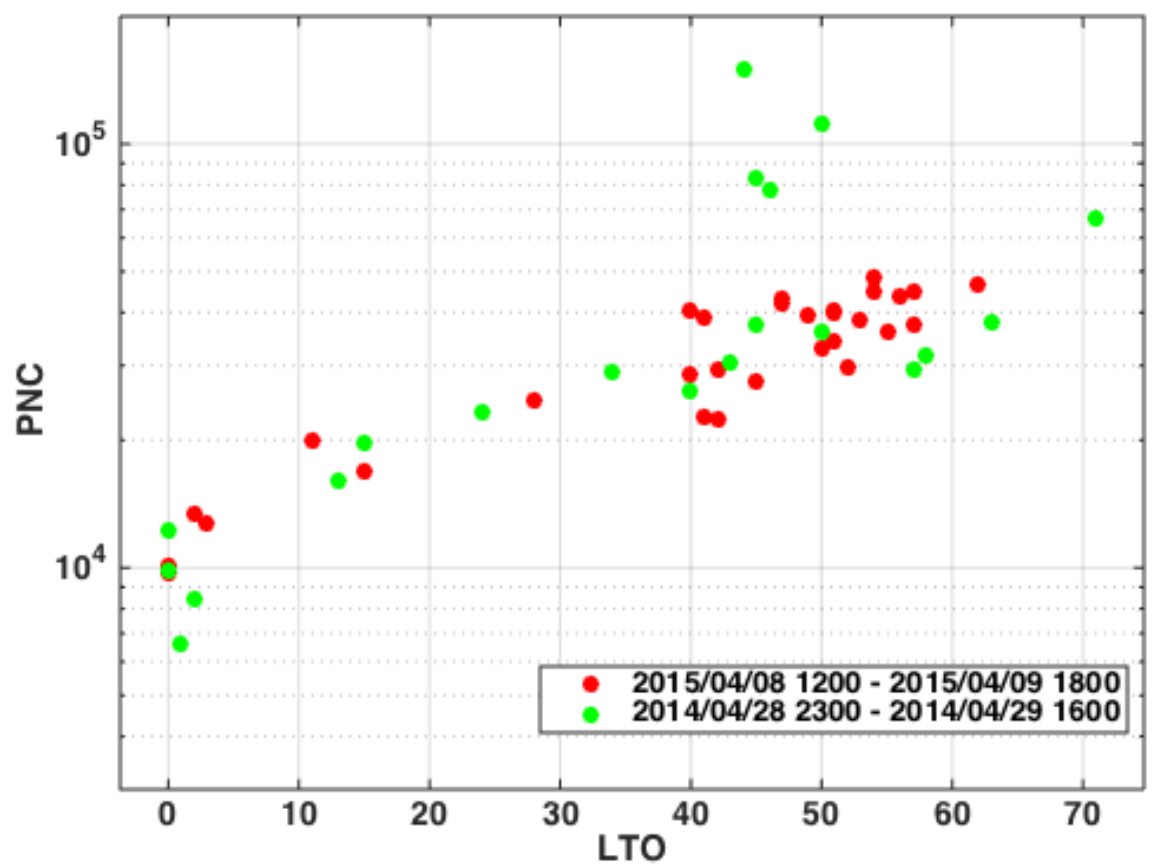

Figure S9 (e): Hourly average PNC vs LTO during the two longest, continuous periods of impact-sector winds at Roxbury site

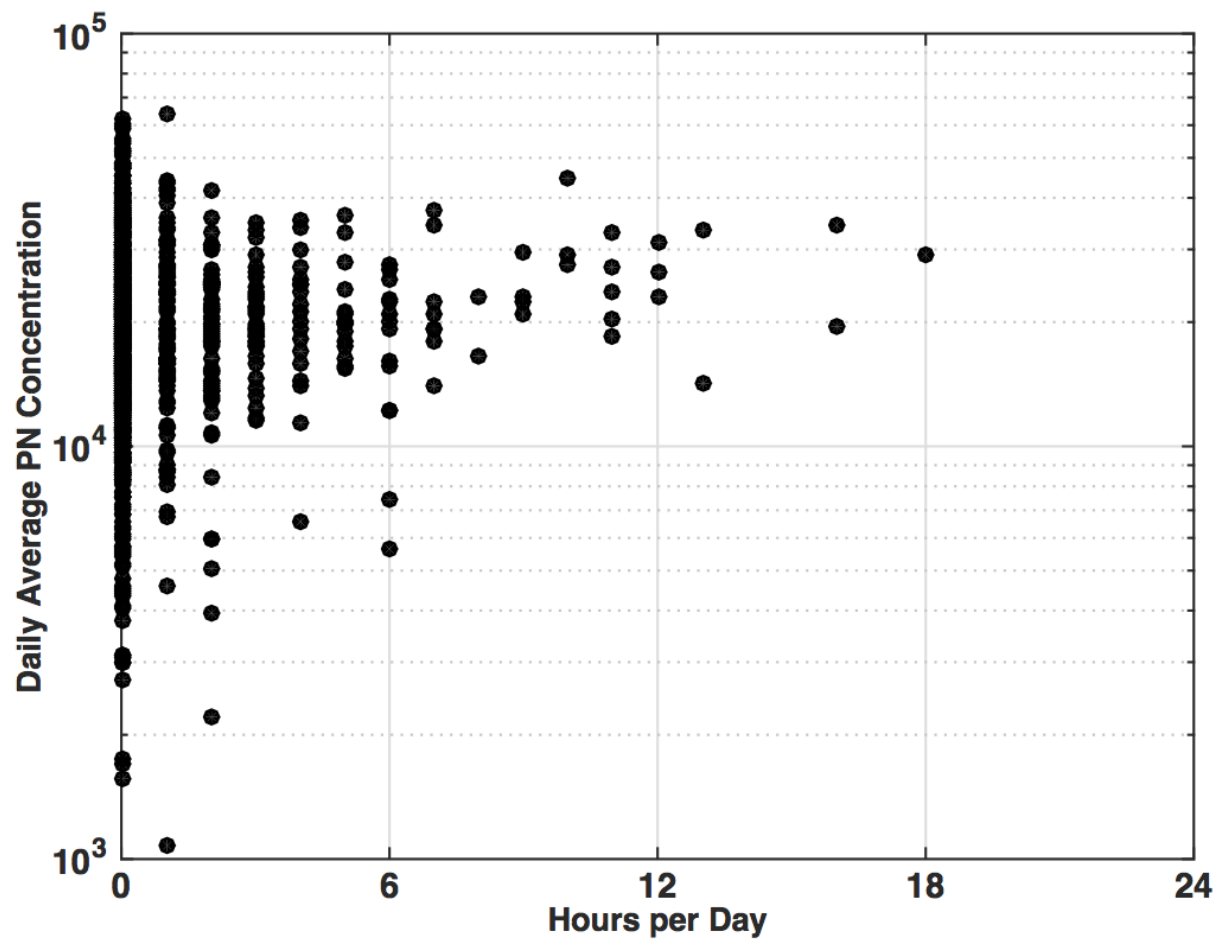

Figure S9 (f): Daily average PNC vs hours of impact-sector winds per day at Roxbury site 


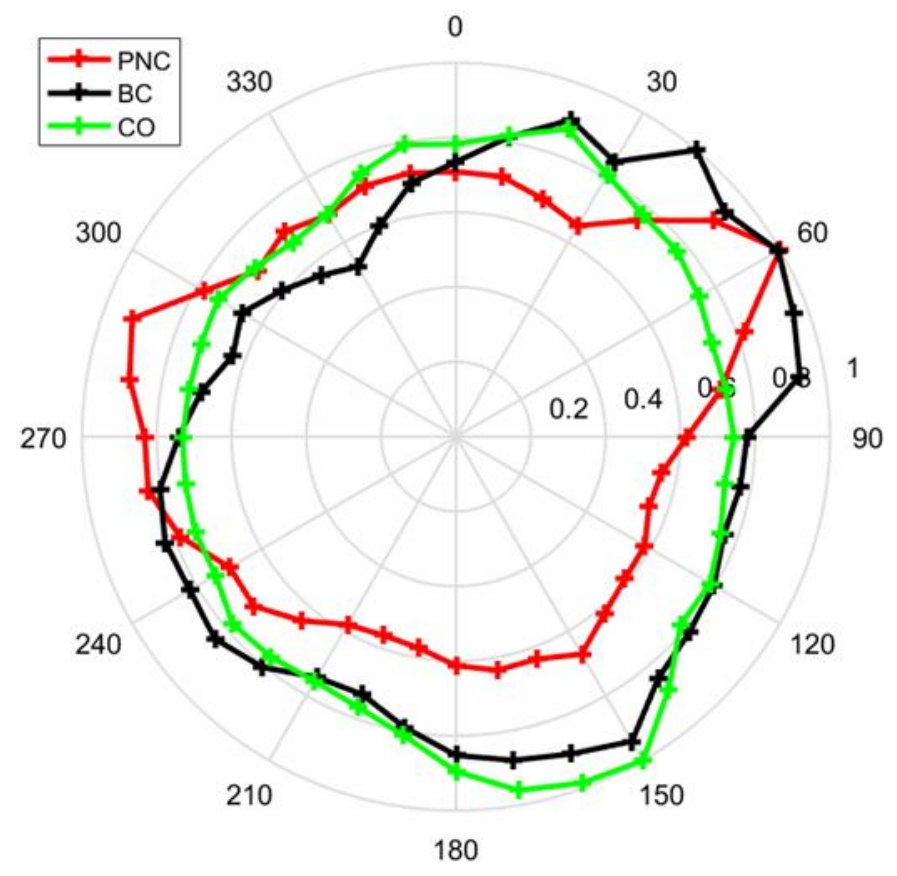

Figure S10 (a): Pollutant roses (normalized by maximum in any $10^{\circ}$-wide sector) for hourly average concentrations measured at Roxbury site.

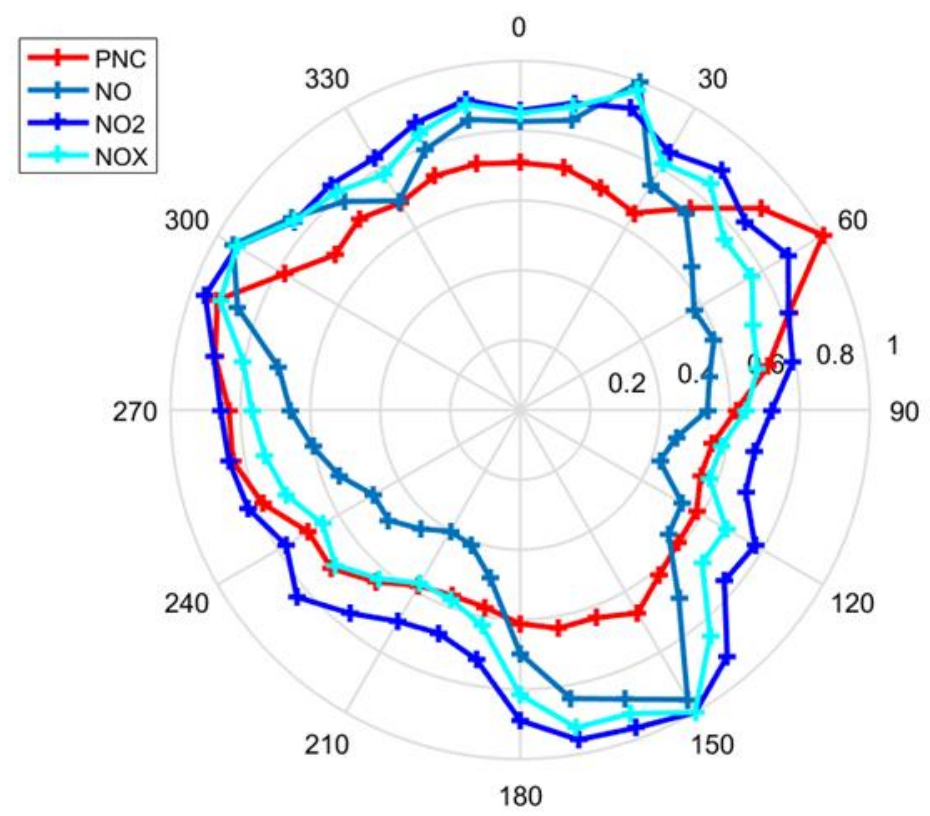

Figure S10 (b): Pollutant roses (normalized by maximum in any $10^{\circ}$-wide sector) for hourly average concentrations measured at Roxbury site. 


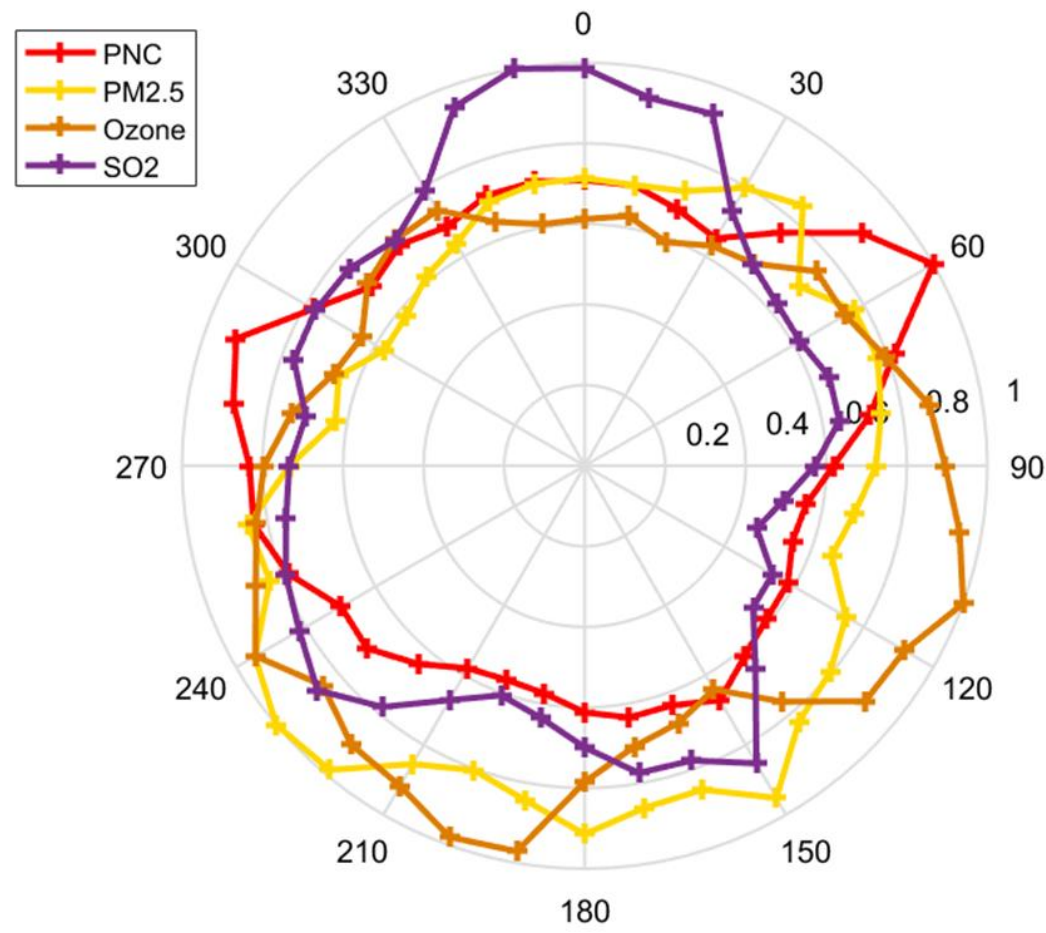

Figure S10 (c): Pollutant roses (normalized by maximum in any $10^{\circ}$-wide sector) for hourly average concentrations measured at Roxbury site. 


\section{Spearman's Partial Correlation Coefficients}

Table S6: Spearman's partial correlation coefficients and p-values for correlation between hourly PNC and LTO at the airport.

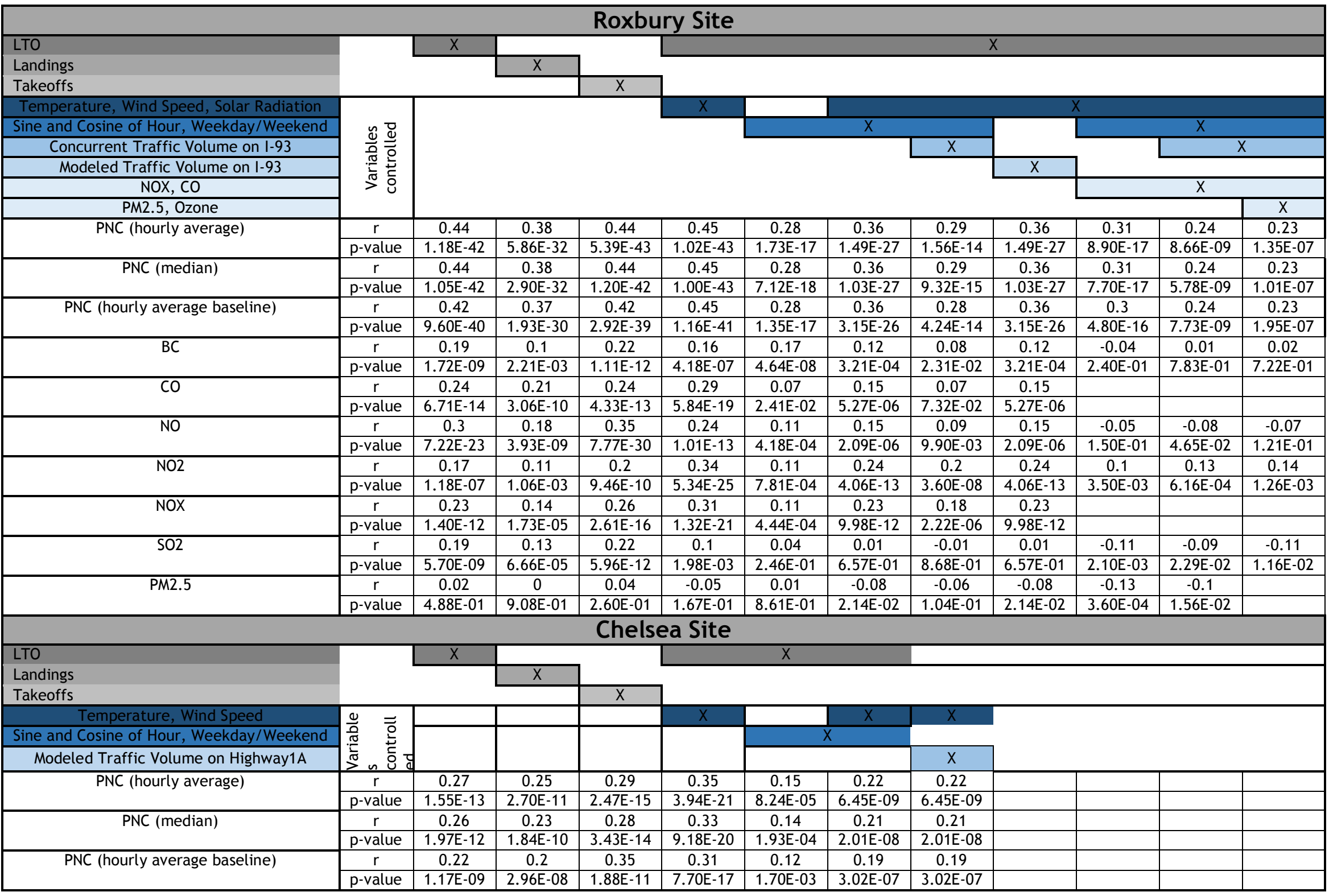




\section{Effect of Wind Speed on Pollutant Concentrations Effect of Wind Speed on PN Concentrations}
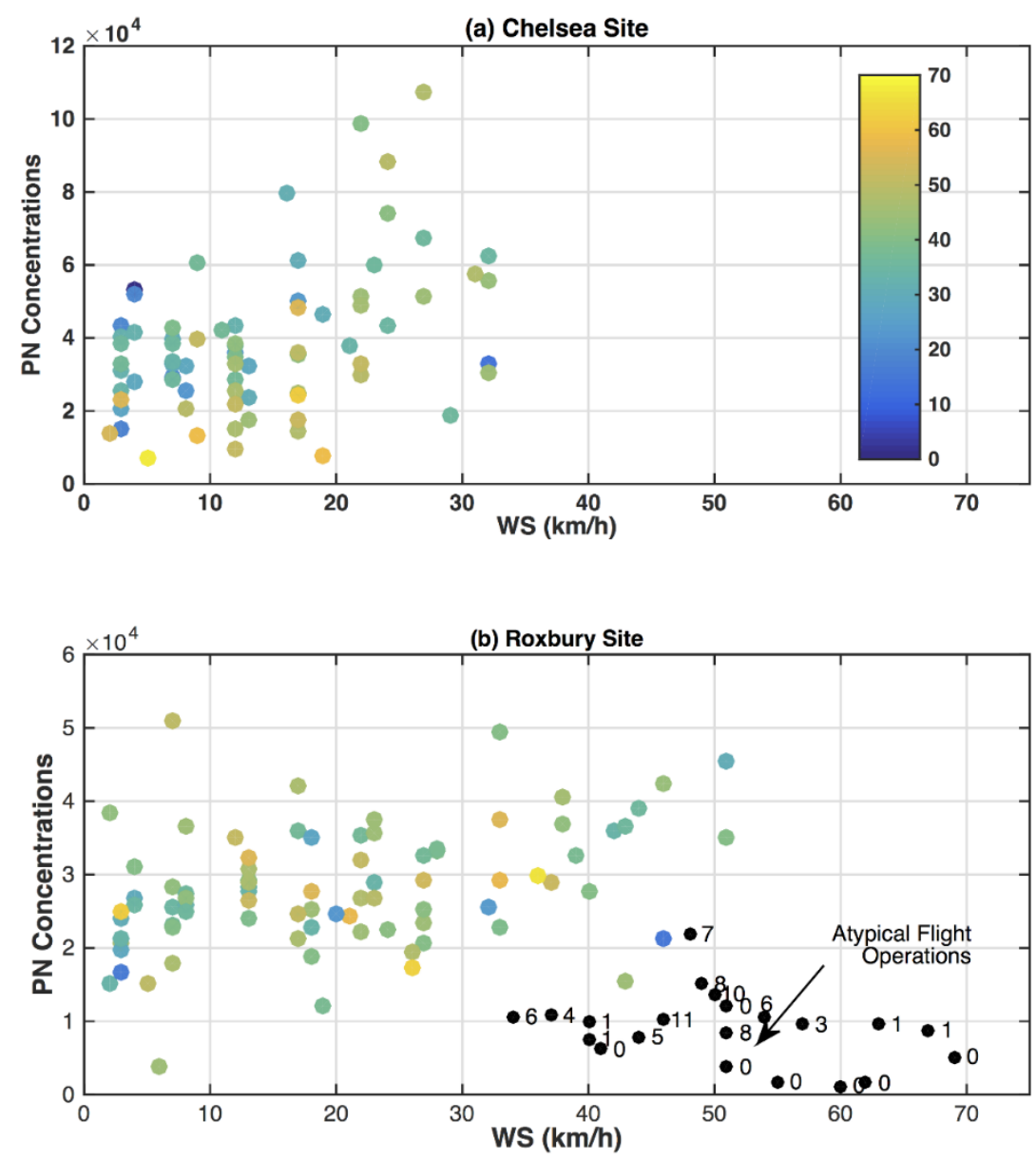

Figure S11 (a)-(b): PN concentration at Chelsea and Roxbury sites aggregated in $5 \mathrm{~km} \mathrm{~h}^{-1}$ wide wind speed and $5^{\circ} \mathrm{C}$ wide ambient temperature bins colored by average LTO. Hours when normal flight operations at Logan were interrupted due to extreme weather are plotted as black dots and data labels show LTO values for these hours.

For hourly data points (and not bin aggregated values), see Figure S12 on the following page. 
(a) Chelsea Site, Impact Sectors

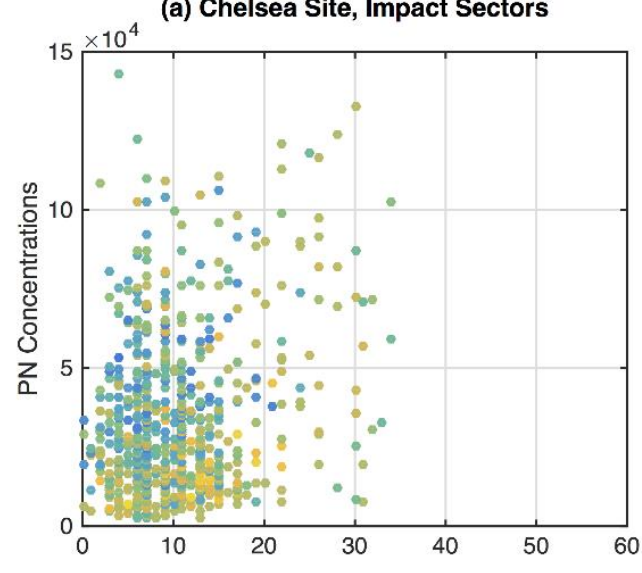

(b) Roxbury Site, Impact Sectors

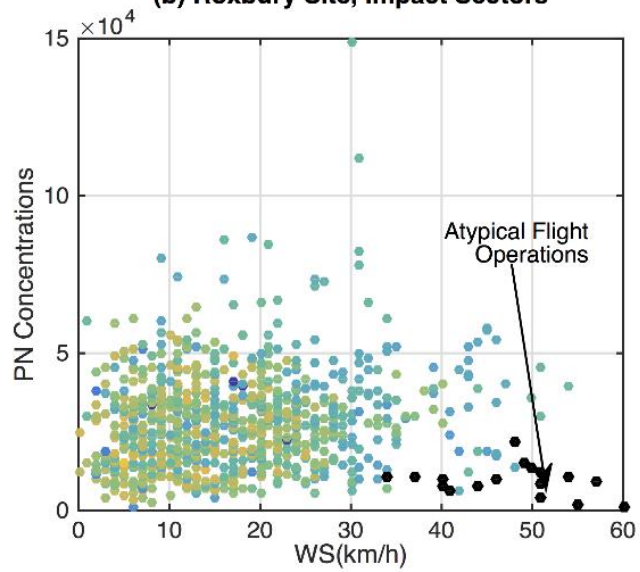

(c) Chelsea Site, Other Sectors

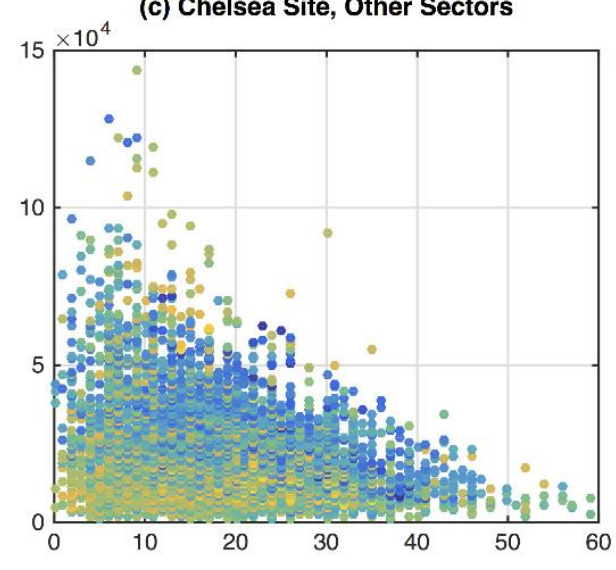

Temp

${ }^{\circ} \mathrm{C}$

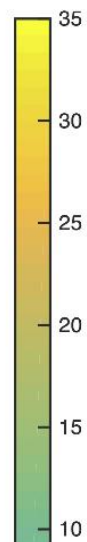

(d) Roxbury Site, Other Sectors

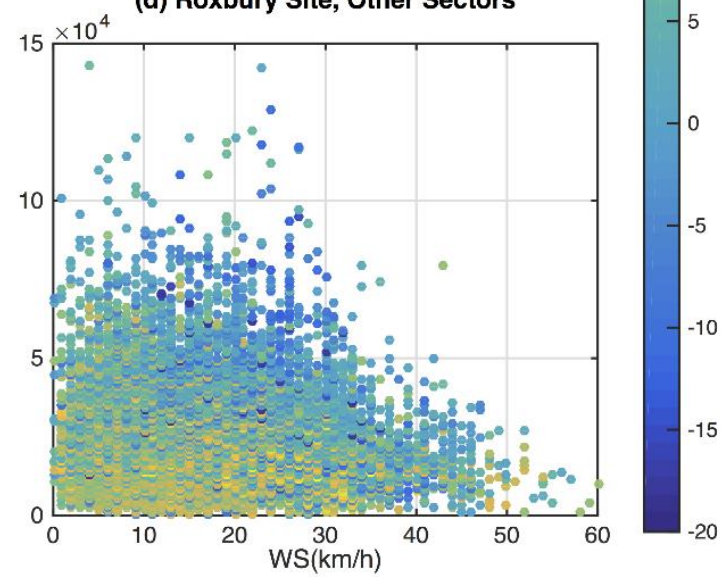

Figure S12 (a)-(d): Hourly PN concentration at Chelsea and Roxbury sites plotted versus hourly average wind speed. Hours when normal flight operations at Logan were interrupted are plotted as black dots. 


\section{Discussion of Data from Hurricane Sandy}

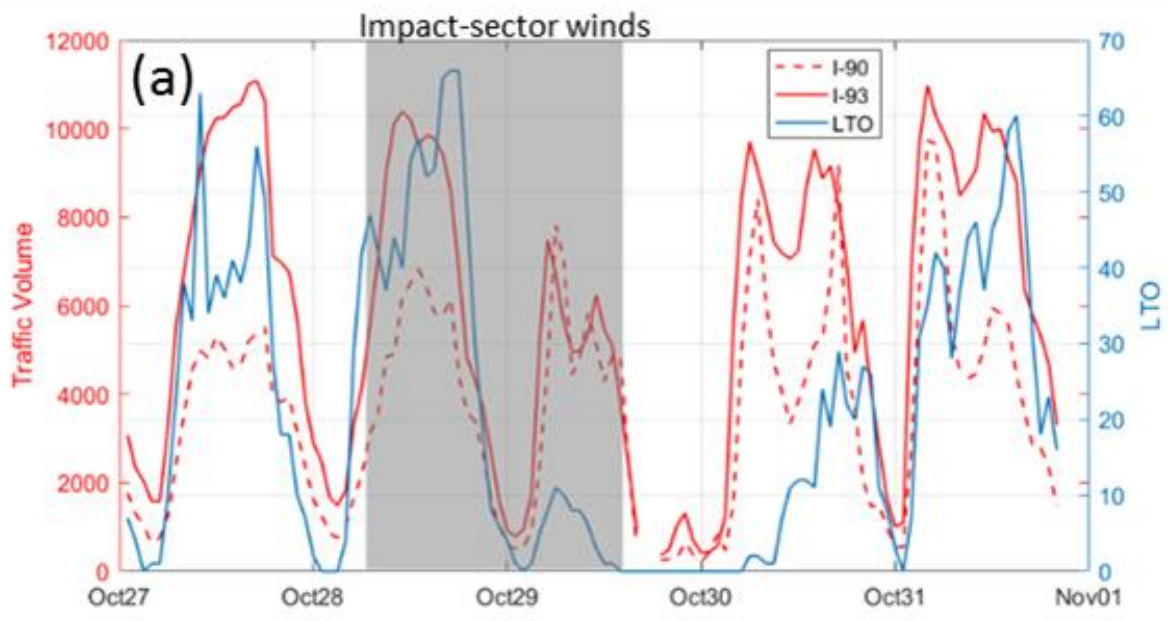

The part of the dataset that had impact-sector winds, i.e., NE, has been highlighted in subfigure (a) that also shows traffic volume on two major interstates in Boston area, I-90 and I93, and LTO at Logan. During impact-sector winds on October 29,

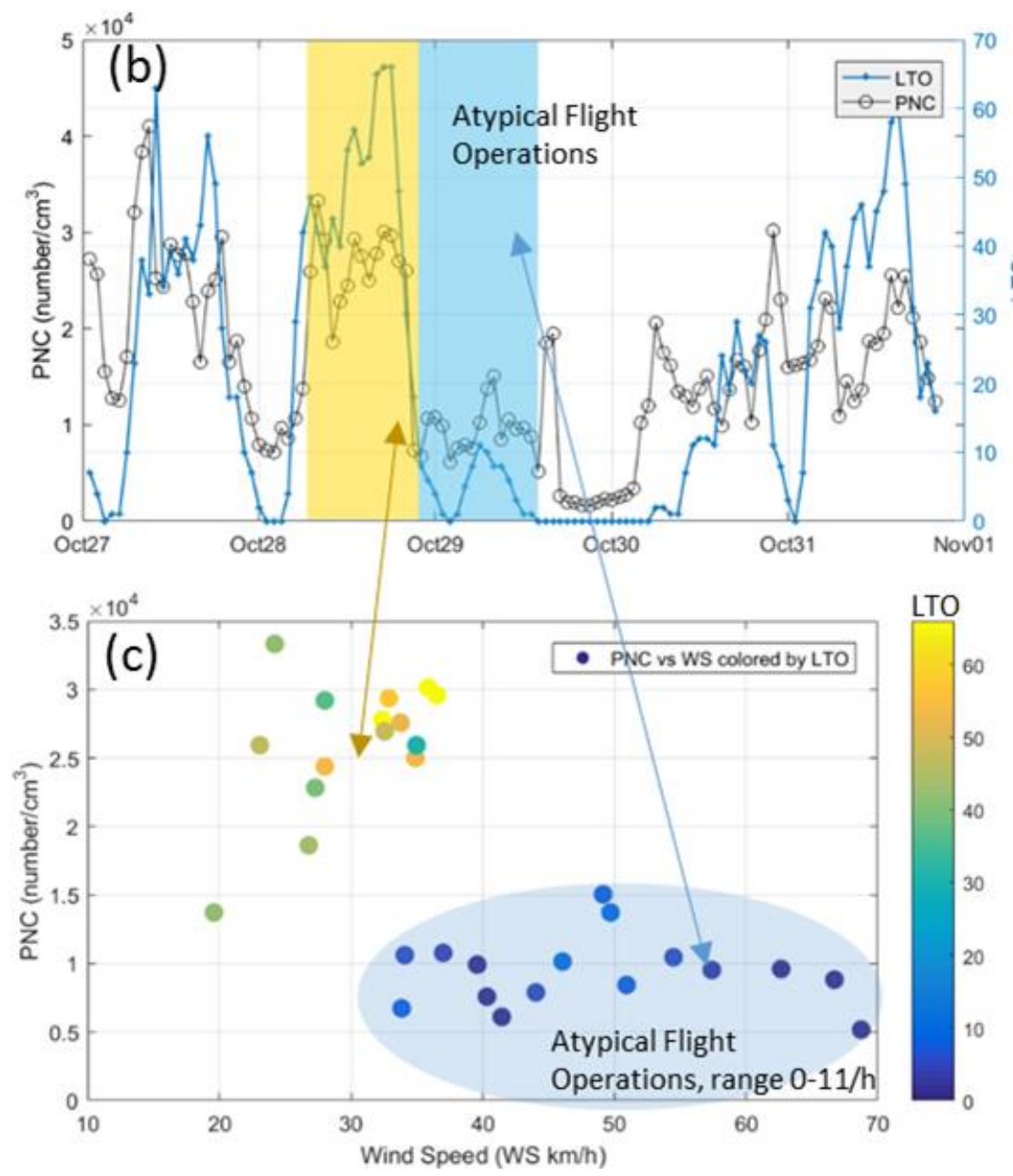
LTO reduction was considerable, 5 per hour from the annual average of 28.5 per hour. LTO reduction is also evident by comparison of October 29 with October 28 in Figure S13. Traffic volume reduction on October 29 was only about a third of its annual average.

Figure S13: (a)-(b) Time-series for traffic activity, LTO, and hourly-average PNC at Roxbury site during Hurricane Sandy, October 27-31, 2012. (c) PNC vs WS with atypical flight operations highlighted. Color ramp is based on LTO/h. 


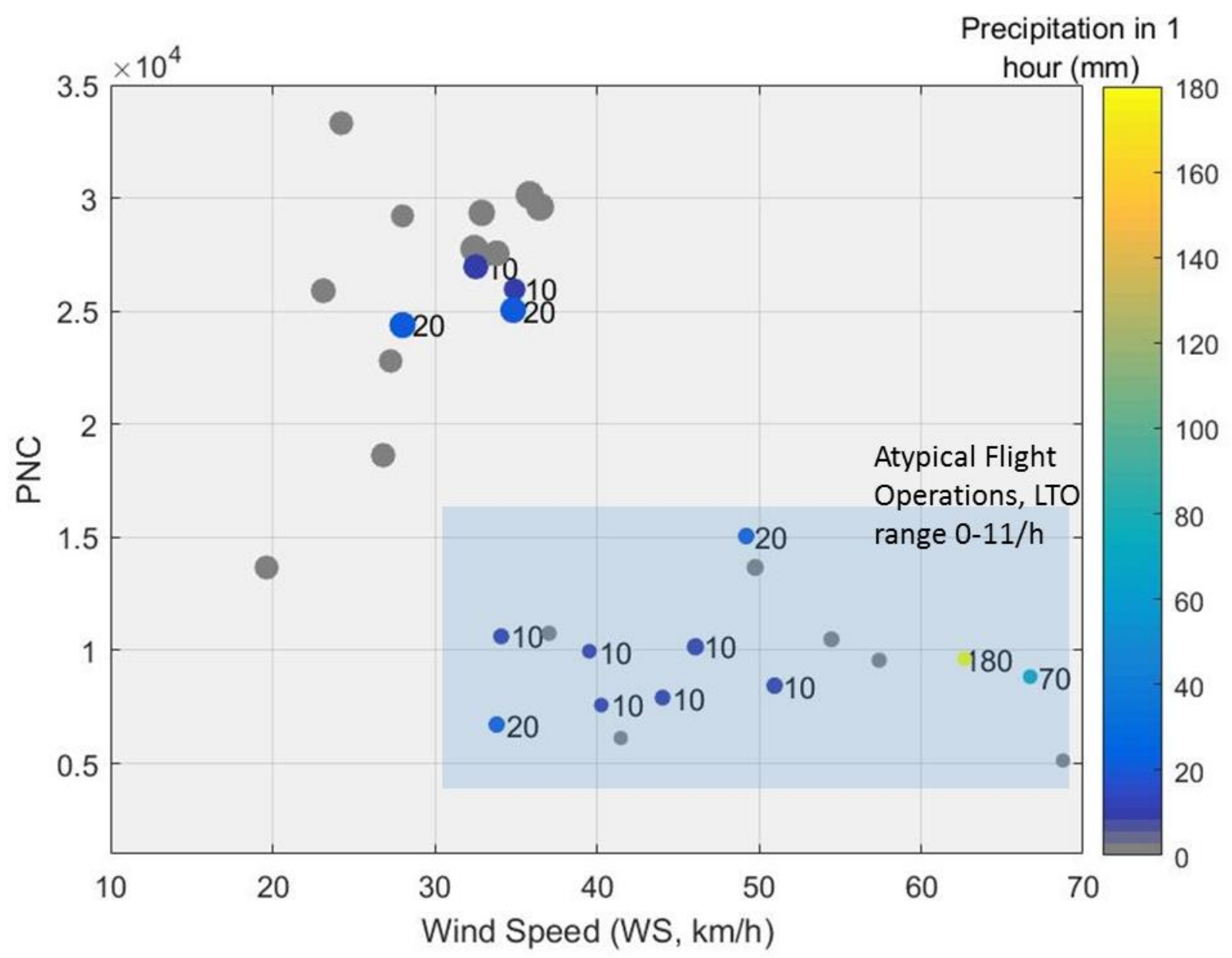

Figure S14: Hourly-average PNC vs WS for impact-sector winds on October 28-29, 2012 during Hurricane Sandy. Dot size is proportional to LTO. Color ramp is based on hourly precipitation $(\mathrm{mm} / \mathrm{h})$ and data labels also indicate hourly precipitation accumulation. 


\section{Effect of Wind Speed on Other Pollutant Concentrations}

The units for the pollutants in the following figure are as follows:

- PNC: number of particles $/ \mathrm{cm}^{3}$

- BC, non-volatile at $25^{\circ} \mathrm{C}$ in PM 2.5 STP: $\mu \mathrm{g} / \mathrm{m}^{3}$

- CO: parts per million

- $\mathrm{NO}, \mathrm{NO}_{2}, \mathrm{NO}_{x}$ and $\mathrm{SO}_{2}$ : parts per billion

(a)

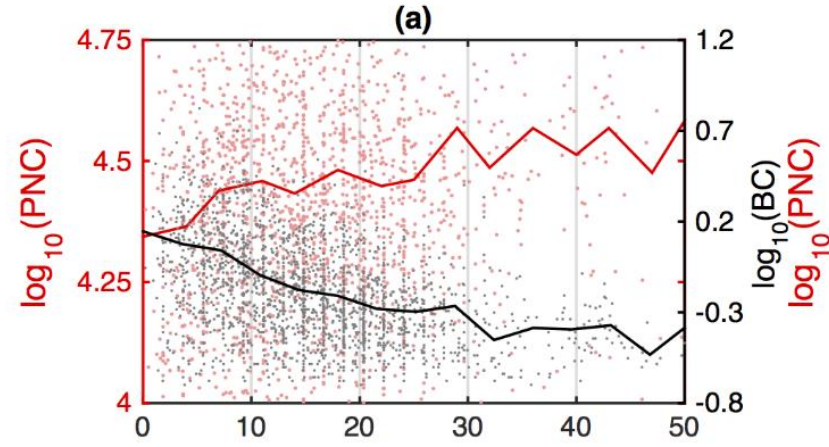

(c)

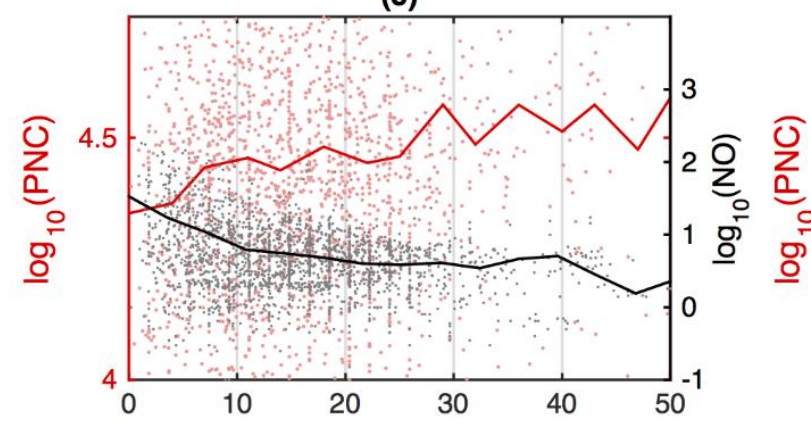

(e)

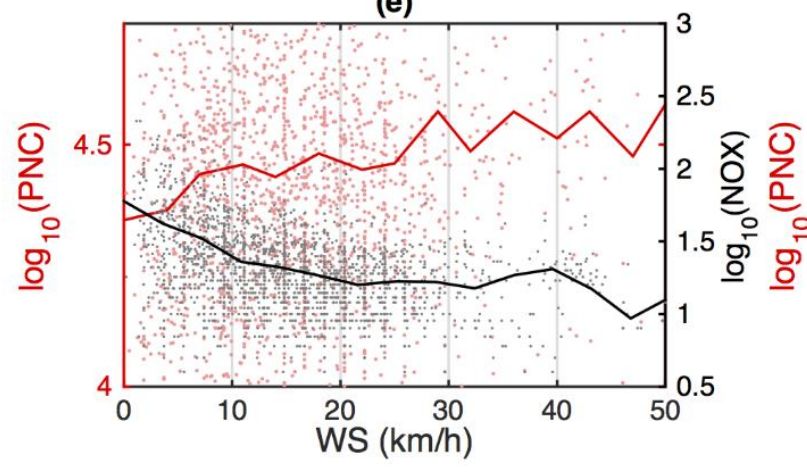

(b)

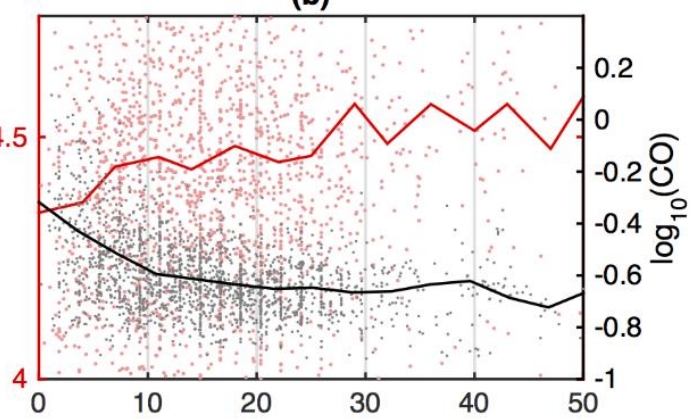

(d)

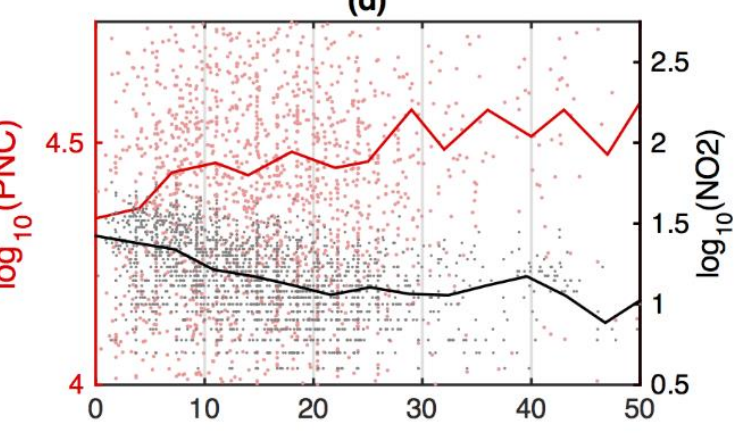

(f)

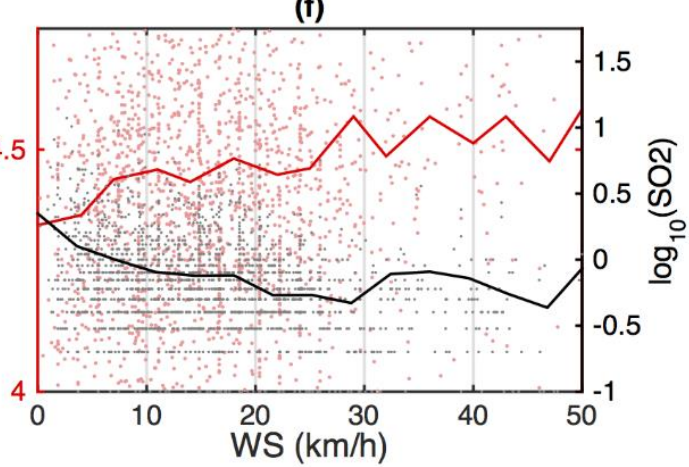

Figure S15 (a)-(f): Wind speed dependence of pollutant concentrations at Roxbury site. Hourly average concentrations of pollutants at Roxbury for impact sector winds are plotted against hourly average wind speed at Logan International Airport (points). Lines show trends in hourly data aggregated by $3.6 \mathrm{~km} \mathrm{~h}^{-1}$ (or $1 \mathrm{~m} \mathrm{~s}^{-1}$ ) wide wind speed bins for PNC (red line) and other pollutants (black lines) for impact sector winds. 
(a)

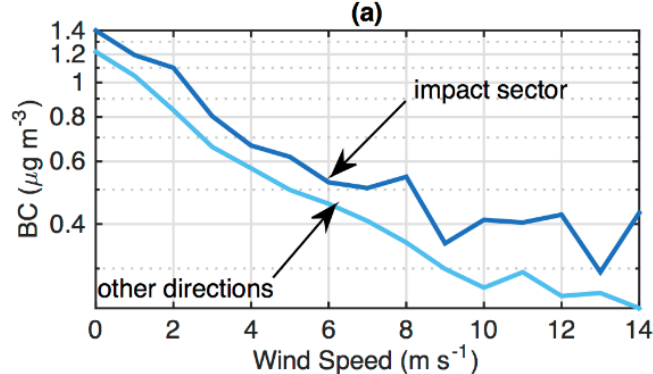

(c)

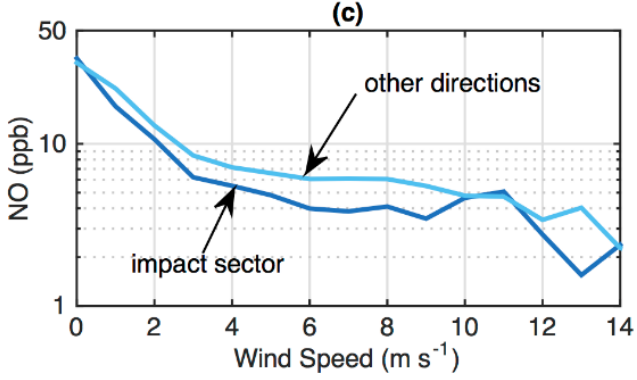

(e)

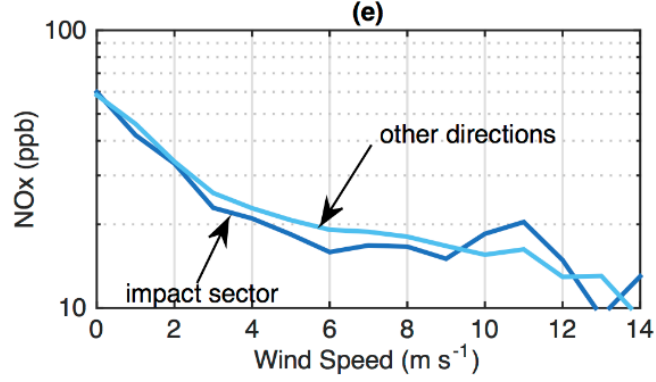

(b)

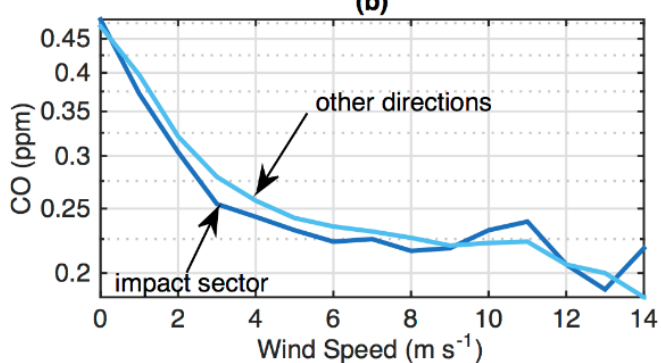

(d)

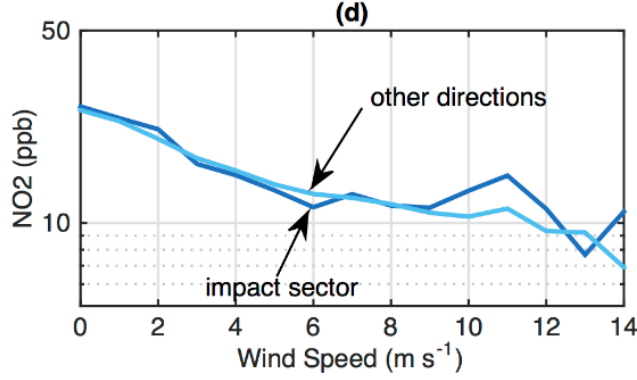

(f)

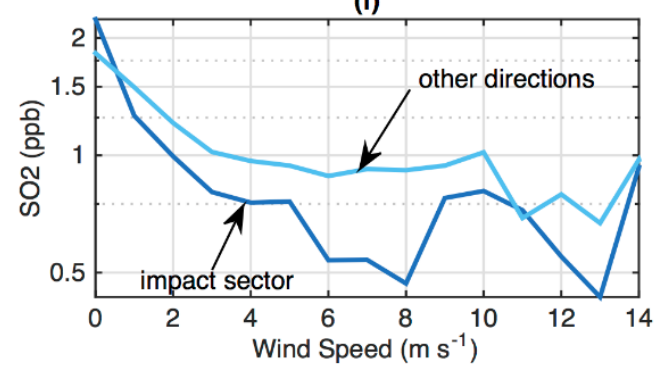

Figure S16 (a)-(f): Wind speed dependence of pollutant concentrations at Roxbury site. Similar trends in hourly data aggregated in $3.6 \mathrm{~km} \mathrm{~h}^{-1}$ (or $1 \mathrm{~m} \mathrm{~s}^{-1}$ ) wide wind speed bins are shown for impact sector and all other wind directions. 


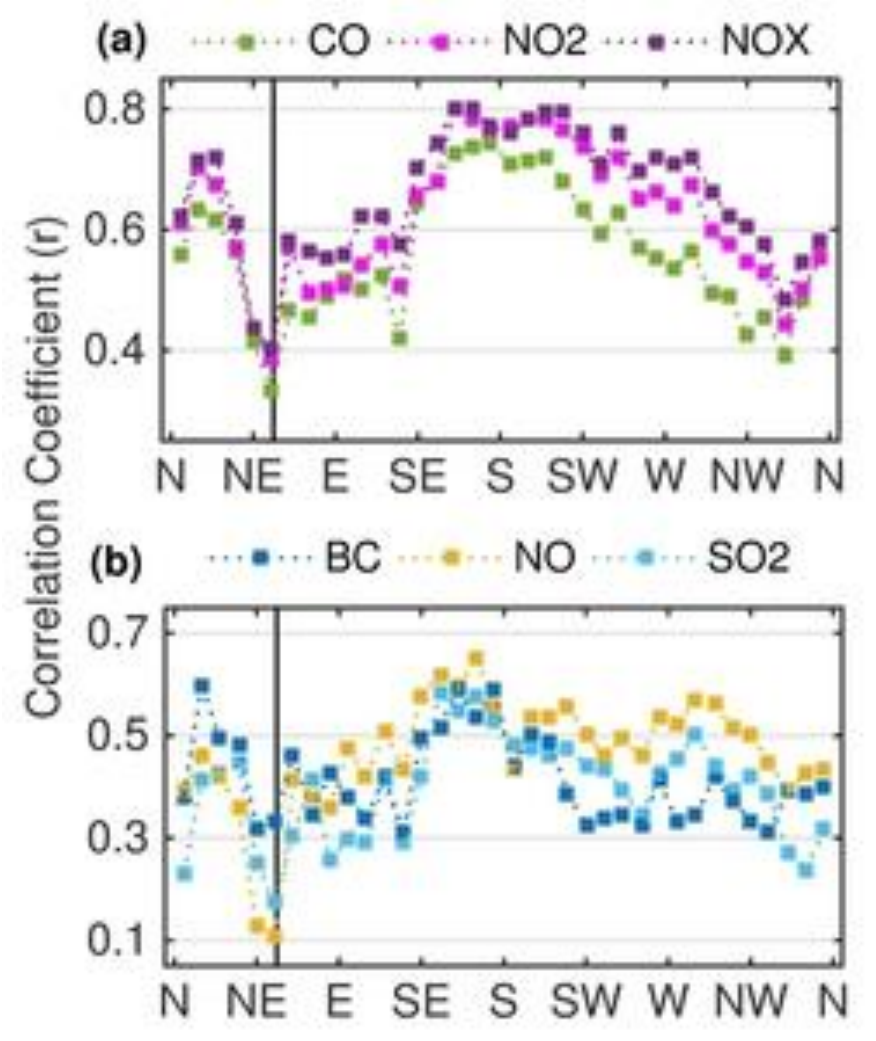

Figure S17 (a)-(b): Correlation (Spearman's rank) between PNC and other pollutant concentrations for $10^{\circ}-$ wide wind sectors at Roxbury site. Vertical line marks the azimuth angle between the site and the airport. 